\title{
Effect of sodium (S)-2-hydroxyglutarate in male, and succinic acid in female Wistar rats against renal ischemia-reperfusion injury, suggesting a role of the HIF-1 pathway
}

\author{
Eduardo Cienfuegos-Pecina ${ }^{1}$, Tannya R Ibarra-Rivera ${ }^{2}$, Alma L Saucedo-Yáñez ${ }^{2}$, Luis A Ramírez-Martínez ${ }^{1}$, \\ Deanna Esquivel-Figueroa ${ }^{1}$, Ixel Domínguez-Vázquez ${ }^{1}$, Karina J Alcántara-Solano ${ }^{1}$, Diana P Moreno-Peña ${ }^{1}$,

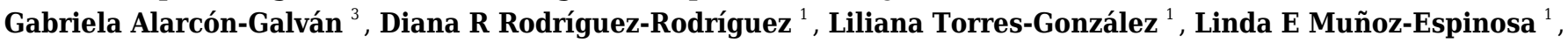 \\ Edelmiro Pérez-Rodríguez ${ }^{4}$, Paula Cordero-Pérez ${ }^{\text {Corresp. } 1}$ \\ ${ }^{1}$ Liver Unit, Department of Internal Medicine, University Hospital “Dr. José E. González”, Universidad Autónoma de Nuevo León, Monterrey, Nuevo León, \\ Mexico \\ 2 Department of Analytical Chemistry, School of Medicine, Universidad Autónoma de Nuevo León, Monterrey, Nuevo León, Mexico \\ 3 Basic Science Department, School of Medicine, Universidad de Monterrey, Monterrey, Nuevo León, Mexico \\ 4 Transplant Service, University Hospital “Dr. José E. González”, Universidad Autónoma de Nuevo León, Monterrey, Nuevo León, Mexico \\ Corresponding Author: Paula Cordero-Pérez \\ Email address: paucordero@yahoo.com.mx
}

Background. Ischemia-reperfusion (IR) injury is the main cause of delayed graft function in solid organ transplantation. Hypoxia-inducible factors (HIFs) control the expression of genes related to preconditioning against IR injury. During normoxia, HIF- $\alpha$ subunits are marked for degradation by the egg-laying defective nine homolog (EGLN) family of prolyl-4-hydroxylases. The inhibition of EGLN stabilizes HIFs and protects against IR injury. The aim of this study was to determine whether the EGLN inhibitors sodium (S)-2-hydroxyglutarate [(S)-2HG] and succinic acid (SA) have a nephroprotective effect against renal IR injury in Wistar rats.

Methods. (S)-2HG was synthesized in a $22.96 \%$ yield from commercially available L-glutamic acid in a two-step methodology (diazotization/alkaline hydrolysis), and its structure was confirmed by nuclear magnetic resonance and polarimetry. SA was acquired commercially. (S)-2HG and SA were independently evaluated in male and female Wistar rats respectively after renal IR injury. Rats were divided into the following groups: sham (SH), nontoxicity [(S)-2HG: 12.5 or $25 \mathrm{mg} / \mathrm{kg}$; SA: 12.5, 25, or $50 \mathrm{mg} / \mathrm{kg}$ ], IR, and compound+IR [(S)-2HG: 12.5 or $25 \mathrm{mg} / \mathrm{kg}$; SA: 12.5, 25, or $50 \mathrm{mg} / \mathrm{kg}$ ]; independent SH and IR groups were used for each assessed compound. Markers of kidney injury (BUN, creatinine, glucose, and uric acid) and liver function (ALT, AST, ALP, LDH, serum proteins, and albumin), proinflammatory cytokines (IL-1 $\beta$, IL-6, and TNF- $\alpha$ ), oxidative stress biomarkers (malondialdehyde and superoxide dismutase), and histological parameters (tubular necrosis, acidophilic casts, and vascular congestion) were assessed. Tissue HIF-1 $\alpha$ was measured by ELISA and Western blot, and the expression of Hmoxl was assessed by RT-qPCR.

Results. (S)-2HG had a dose-dependent nephroprotective effect, as evidenced by a significant reduction in the changes in the BUN, creatinine, ALP, AST, and LDH levels compared with the IR group. Tissue HIF-1 $\alpha$ was only increased in the IR group compared to SH, however, (S)-2HG caused a significant increase in the expression of Hmoxl, suggesting an early accumulation of HIF-1 $\alpha$ in the (S)-2HG-treated groups. There were no significant effects on the other biomarkers. SA did not show a nephroprotective effect; the only changes were a decrease in creatinine level at $12.5 \mathrm{mg} / \mathrm{kg}$ and increased IR injury at 50 $\mathrm{mg} / \mathrm{kg}$. There were no effects on the other biochemical, proinflammatory, or oxidative stress biomarkers.

Peer) reviewing PDF | (2020:01:44918:1:1:CHECK 27 May 2020) 
Conclusion. None of the compounds were hepatotoxic at the tested doses. (S)-2HG showed a dosedependent nephroprotective effect at the evaluated doses, which involved an increase in the expression of Hmox1, suggesting stabilization of HIF-1 $\alpha$. SA did not show a nephroprotective effect but tended to increase IR injury when given at high doses. 
1 Effect of sodium (S)-2-hydroxyglutarate in male, and

2 succinic acid in female Wistar rats against renal

3 ischemia-reperfusion injury, suggesting a role of the

4 HIF-1 pathway

5

6

7

8

9

10

11

12

13

14

15

Eduardo Cienfuegos-Pecina ${ }^{1}$, Tannya R. Ibarra-Rivera ${ }^{2}$, Alma L. Saucedo-Yáñez ${ }^{2}$, Luis A. Ramírez-Martínez ${ }^{1}$, Deanna Esquivel-Figueroa ${ }^{1}$, Ixel Domínguez-Vázquez ${ }^{1}$, Karina J. AlcántaraSolano ${ }^{1}$, Diana P. Moreno-Peña ${ }^{1}$, Gabriela Alarcón-Galván ${ }^{3}$, Diana R. Rodríguez-Rodríguez ${ }^{1}$, Liliana Torres-González ${ }^{1}$, Linda E. Muñoz-Espinosa ${ }^{1}$, Edelmiro Pérez-Rodríguez ${ }^{4}$, Paula Cordero-Pérez ${ }^{1}$

${ }^{1}$ Liver Unit, Department of Internal Medicine, University Hospital "Dr. José E. González", Universidad Autónoma de Nuevo León, Monterrey, Nuevo León, Mexico

${ }^{2}$ Department of Analytical Chemistry, School of Medicine, Universidad Autónoma de Nuevo León, Monterrey, Nuevo León, Mexico

${ }^{3}$ Basic Science Department, School of Medicine, Universidad de Monterrey, Monterrey, Nuevo León, Mexico

${ }^{4}$ Transplant Service, University Hospital “Dr. José E. González", Universidad Autónoma de Nuevo León, Monterrey, Nuevo León, Mexico

Corresponding Author:

Paula Cordero-Pérez ${ }^{1}$

Av. Gonzalitos \#235 Col. Mitras Centro, Monterrey, Nuevo León, 64460, Mexico

Email address: paucordero@yahoo.com.mx

\section{Abstract}

Background. Ischemia-reperfusion (IR) injury is the main cause of delayed graft function in solid organ transplantation. Hypoxia-inducible factors (HIFs) control the expression of genes related to preconditioning against IR injury. During normoxia, HIF- $\alpha$ subunits are marked for degradation by the egg-laying defective nine homolog (EGLN) family of prolyl-4-hydroxylases. The inhibition of EGLN stabilizes HIFs and protects against IR injury. The aim of this study was to determine whether the EGLN inhibitors sodium $(S)$-2-hydroxyglutarate $[(S)-2 \mathrm{HG}]$ and succinic acid (SA) have a nephroprotective effect against renal IR injury in Wistar rats.

Methods. (S)-2HG was synthesized in a $22.96 \%$ yield from commercially available L-glutamic acid in a two-step methodology (diazotization/alkaline hydrolysis), and its structure was confirmed by nuclear magnetic resonance and polarimetry. SA was acquired commercially. (S)$2 \mathrm{HG}$ and SA were independently evaluated in male and female Wistar rats respectively after 
39

40

41

42

43

44

45

46

47

48

49

50

51

52

53

54

55

56

57

58

59

60

61

62

63

64

65

66

67

68

69

70

71

72

73

74

75

76

77

renal IR injury. Rats were divided into the following groups: sham (SH), nontoxicity [(S)-2HG: 12.5 or $25 \mathrm{mg} / \mathrm{kg}$; SA: $12.5,25$, or $50 \mathrm{mg} / \mathrm{kg}$ ], IR, and compound+IR [(S)-2HG: 12.5 or 25 $\mathrm{mg} / \mathrm{kg}$; SA: $12.5,25$, or $50 \mathrm{mg} / \mathrm{kg}$ ]; independent $\mathrm{SH}$ and IR groups were used for each assessed compound. Markers of kidney injury (BUN, creatinine, glucose, and uric acid) and liver function (ALT, AST, ALP, LDH, serum proteins, and albumin), proinflammatory cytokines (IL-1 $\beta$, IL-6, and TNF- $\alpha$ ), oxidative stress biomarkers (malondialdehyde and superoxide dismutase), and histological parameters (tubular necrosis, acidophilic casts, and vascular congestion) were assessed. Tissue HIF- $1 \alpha$ was measured by ELISA and Western blot, and the expression of Hmox 1 was assessed by RT-qPCR.

Results. (S)-2HG had a dose-dependent nephroprotective effect, as evidenced by a significant reduction in the changes in the BUN, creatinine, ALP, AST, and LDH levels compared with the IR group. Tissue HIF-1 $\alpha$ was only increased in the IR group compared to SH, however, $(S)-2 \mathrm{HG}$ caused a significant increase in the expression of Hmox 1, suggesting an early accumulation of HIF-1 $\alpha$ in the $(S)$-2HG-treated groups. There were no significant effects on the other biomarkers. SA did not show a nephroprotective effect; the only changes were a decrease in creatinine level at $12.5 \mathrm{mg} / \mathrm{kg}$ and increased IR injury at $50 \mathrm{mg} / \mathrm{kg}$. There were no effects on the other biochemical, proinflammatory, or oxidative stress biomarkers.

Conclusion. None of the compounds were hepatotoxic at the tested doses. (S)-2HG showed a dose-dependent nephroprotective effect at the evaluated doses, which involved an increase in the expression of Hmox 1, suggesting stabilization of HIF-1 $\alpha$. SA did not show a nephroprotective effect but tended to increase IR injury when given at high doses.

\section{Introduction}

Kidney transplantation is the definitive treatment for patients with end-stage chronic kidney disease. However, the shortage of available organs for transplantation is a formidable challenge. In Mexico, about five patients are on a waiting list for each available kidney (CENATRA 2018). Despite the advances in knowledge about histocompatibility and immunosuppression, few steps have been taken to ameliorate the effects of ischemia-reperfusion (IR) injury during organ procurement. IR injury is one of the main causes of delayed graft function and is an important risk factor during surgical procedures such as thoracic, peripheral vascular, and major vascular surgery (Chen \& Date 2015; Salvadori et al. 2015).

IR injury is a complex process that occurs when blood flow to an organ is impaired for a long period of time and then is suddenly restarted, perfusing the organ with oxygenated blood. This process is characterized by the release of reactive oxygen species (ROS), which involves several metabolic pathways such as the degradation of purine nucleotides (Granger 1988; McManaman $\&$ Bain 2002). During reperfusion, large amounts of oxygen enter the cellular microenvironment, where it leads to the production of superoxide radicals, $\mathrm{HClO}$, and $\mathrm{H}_{2} \mathrm{O}_{2}$ (Welbourn et al. 1991). 
78 In addition, depletion of ATP during hypoxia causes alterations in mitochondrial function,

79 inducing cytochrome c release, and apoptosis (Dorweiler et al. 2007).

80

81 Diverse strategies have been developed to prevent or limit IR injury, such as preconditioning 82 drugs (hypoxia mimetics) and techniques such as ischemic preconditioning (IPC) (Murry et al.

83 1986) and remote ischemic preconditioning (RIPC) (Przyklenk et al. 1993). A key mechanism in

84 IR injury prevention by IPC and RIPC appears to be the upregulation of the family of hypoxia-

85 inducible factors (HIFs) (Randhawa et al. 2015).

86

87

HIFs are a family of transcription factors that act as regulators of oxygen homeostasis in cells

88 (Semenza 2014). These transcription factors function as heterodimers whose structure includes an $\alpha$-subunit, which is regulated by oxygen concentration, and a $\beta$-subunit, which is expressed constitutively and is not oxygen dependent (Dengler et al. 2014; Kaelin \& Ratcliffe 2008; Wang \& Semenza 1995). HIF family members stimulate the transcription of many genes, such as $H M O X 1, E P O, V E G F, L D H$, and PDK1 (Semenza 2014). The most relevant of the HIF family is HIF-1 $\alpha$ (Wang \& Semenza 1995). During normoxia, the $\alpha$-subunit is hydroxylated at Pro-402 and Pro-564 residues by the egg-laying defective nine homolog (EGLN) family of prolyl-4hydroxylases (Ivan et al. 2001; Jaakkola et al. 2001). EGLN-1 is the family member with the greatest affinity for HIF-1 $\alpha$ (Appelhoff et al. 2004; Karuppagounder \& Ratan 2012). Hydroxylated $\alpha$-subunits are ubiquitinated by the von Hippel-Lindau E3 ubiquitin ligase and degraded in the proteasome (Ohh et al. 2000). EGLN family members are $\alpha$-ketoglutaratedependent dioxygenases (Bruick \& McKnight 2001; Jaakkola et al. 2001), and inhibition of

100

101

102

103

104

105

106

107

108

109

110

111

112

113

114

115 116 EGLN members stimulates HIF-1 $\alpha$ accumulation (Hill et al. 2008). For that reason, these enzymes are considered to be a potential therapeutic target and have shown great promise in preclinical studies (Bernhardt et al. 2009; Hill et al. 2008).

A well-known EGLN inhibitor is 2-hydroxyglutarate (2HG), which was the first oncometabolite to be reported in the literature (Dang et al. 2009). Because of the structural analogy between $\alpha-$ ketoglutarate and $2 \mathrm{HG}$, the latter possesses an inhibitory effect on several $\alpha$-ketoglutaratedependent dioxygenases, such as EGLN family members, increasing the intracellular concentration of HIF-1 $\alpha$ (Xu et al. 2011). It has been shown that the $(S)-2 \mathrm{HG}$ enantiomer has a stronger inhibitory activity than the $(R)-2 \mathrm{HG}$ enantiomer, which can also act as a weak activator of EGLN-1 without promoting HIF-1 $\alpha$ accumulation (Koivunen et al. 2012; Xu et al. 2011).

Several Krebs cycle metabolites also have EGLN-inhibitory activity. In vitro studies show that succinic acid (SA) inhibits EGLN family members because of its structural analogy with $\alpha$ ketoglutarate and because of a possible product inhibition mechanism (Koivunen et al. 2007; Myllyharju 2009), although additional data are needed to understand the role of SA in IR injury. 
117 Given the reported activities and potential pharmacological properties of these compounds, the 118 aim of this study was to determine whether the administration of EGLN inhibitors, $(S)$-2HG and 119 SA, before induction of IR injury would have a nephroprotective effect in Wistar rats.

120

\section{1}

122

123

124

125

126

127

128

129

130

131

132

133

134

135

136

137

138

139

140

141

142

143

144

145

146

147

148

149

150

151

152

153

154

155

\section{Materials \& Methods}

\section{Sodium ( $S$ )-2HG synthesis}

$(S)-2 \mathrm{HG}$ was synthesized in two steps using a modification of previously reported methods (Bauer \& Gajewiak 2004; Kolitz et al. 2009). L-glutamic acid (Sigma-Aldrich, Saint Louis, MO, USA) was submitted to a diazotization reaction, which produced (S)-5-oxotetrahydrofuran-2carboxylic acid (MW: $130.10 \mathrm{~g} / \mathrm{mol}$ ), followed by alkaline hydrolysis, which produced sodium (S)-2HG (MW: $192.08 \mathrm{~g} / \mathrm{mol}$ ) (Fig. 1).

\section{(S)-5-oxotetrahydrofuran-2-carboxylic acid.}

A solution of $2.9426 \mathrm{~g}(20 \mathrm{mmol})$ of L-glutamic acid in $80 \mathrm{~mL}$ of $0.5 \mathrm{M} \mathrm{H}_{2} \mathrm{SO}_{4}$ was prepared and cooled to $0^{\circ} \mathrm{C}$ in an ice bath. A solution of $8.2788 \mathrm{~g}(120 \mathrm{mmol})$ of $\mathrm{NaNO}_{2}$ in $30 \mathrm{~mL}$ of doubledistilled water was then added drop by drop. The reaction was performed at room temperature for $24 \mathrm{~h}$ with continuous stirring and then saturated with $\mathrm{NaCl}$ and extracted three times with 100 $\mathrm{mL}$ of ethyl acetate. The organic phase was recovered and dried with anhydrous $\mathrm{Na}_{2} \mathrm{SO}_{4}$. The solvent was low-pressure evaporated at $37^{\circ} \mathrm{C}$, and the synthesis product was purified in a silica column using an ethyl acetate mobile phase. Fractions of $5 \mathrm{~mL}$ were recovered and evaluated using thin layer chromatography with silica as the stationary phase and ethyl acetate as the mobile phase. The fractions containing the purified synthesis product were recovered, and the solvent was low-pressure evaporated at $37^{\circ} \mathrm{C}$.

\section{Sodium (S)-2HG.}

To synthesize $(S)$-2HG, $1.1329 \mathrm{~g}(8.7079 \mathrm{mmol})$ of $(S)$-5-oxotetrahydrofuran-2-carboxylic acid was dissolved in $100 \mathrm{~mL}$ of double-distilled water. A $10 \mathrm{M}$ aqueous solution of $\mathrm{NaOH}$ was added drop by drop until a $\mathrm{pH}$ of 10 was reached, and the solution was subjected to continuous stirring for $2 \mathrm{~h}$ at room temperature. Most of the solvent was low-pressure coevaporated with ethanol at $37^{\circ} \mathrm{C}$. The reaction product was warmed in an oil bath, removed from the heat, and precipitated with anhydrous methanol. (S)-2HG crystals were recovered using a vacuum filtration system.

\section{Characterization by nuclear magnetic resonance}

Nuclear magnetic resonance (NMR) data were acquired using a Bruker AVANCE III HD 400 MHz spectrometer (Bruker Corp., Billerica, MA, USA). A (S)-5-oxotetrahydrofuran-2carboxylic acid sample was dissolved in $\mathrm{CDCl}_{3}$ with $0.03 \% v / v$ tetramethylsilane (SigmaAldrich) and transferred to $5 \mathrm{~mm}$ NMR standard tubes. (S)-2HG was dissolved in doubledistilled water. The $(S)-2 \mathrm{HG}$ aqueous solution was analyzed inside a $5 \mathrm{~mm}$ NMR tube using a 
156

157

158

159

160

161

162

163

164

165

166

167

168

169

170

171

172

173

174

175

176

177

178

179

180

181

182

183

184

185

186

187

188

189

190

191

192

193

194

195

coaxial system (Wilmad ${ }^{\circledR}$ coaxial insert, Wilmad-LabGlass, Vineland, NJ, USA), filled with $\mathrm{D}_{2} \mathrm{O}$ with $0.75 \%$ sodium 3-(trimethylsilyl)propionate-2,2,3,3-d $\mathrm{d}_{4}$ (TSP) (Sigma-Aldrich).

${ }^{1} \mathrm{H}$ and ${ }^{13} \mathrm{C}$-NMR spectra of $(S)$-5-oxotetrahydrofuran-2-carboxylic acid were obtained using standard acquisition parameters. The $(S)-2 \mathrm{HG}$ proton spectrum was acquired using the noesyprld pulse sequence for water signal suppression. Compounds were identified by comparing the obtained data with previously reported spectra (Bal \& Gryff-Keller 2002). DEPT-135, HMBC, and HSQC spectra were also acquired. Relative $(S)$-2HG purity was determined by the integration of all the signals of the ${ }^{1} \mathrm{H}-\mathrm{NMR}$ spectrum, with exception of the ${ }^{13} \mathrm{C}$ couplings and the TSP signal using a method similar to published chromatographic procedures (Pauli et al. 2007). The obtained data were processed and analyzed using Bruker TopSpin 3.2 software (Bruker Corp.) and used to confirm $(S)-2 \mathrm{HG}$ synthesis.

\section{Determination of Sodium (S)-2HG optical activity}

The specific optical rotation $\left([\alpha]_{\mathrm{D}}{ }^{20^{\circ} \mathrm{C}}\right)$ of a $0.0944 \mathrm{~g} / \mathrm{mL}$ aqueous solution of $(S)-2 \mathrm{HG}$ was determined at $20^{\circ} \mathrm{C}$ using the sodium D-line $(\lambda=589 \mathrm{~nm})$ in a PerkinElmer 341 Polarimeter (PerkinElmer, Waltham, MA, USA) with a $50 \mathrm{~mm}$ cell.

\section{Animals}

The animal procedures were performed according to the specifications of the Official Mexican Norm NOM-062-ZOO-1999. This project was approved by the Ethics and Research Committee of the School of Medicine, Universidad Autónoma de Nuevo León (Register number HI170002). Wistar rats, weighing 250-300 g, were used: 32 male rats to evaluate $(S)-2 \mathrm{HG}$ activity and 42 females to evaluate SA activity. We randomly decided to use male or female rats for each assessed compound based on the availability of animals in our laboratory. Male and female rats exert a different behavior after induction of IR injury (Robert et al. 2011). Hence, we used independent control groups for each assessed compound. The rats were kept under standard conditions such as stable room temperature $\left(24 \pm 3^{\circ} \mathrm{C}\right)$ and $12 \mathrm{~h}$ light-dark cycle and had access to commercial rat pellets (Nutrimix de México, S.A. de C.V., Mexico City, Mexico) and water ad libitum.

\section{Experimental design}

\section{Dose selection}

To our knowledge, neither $(S)-2 \mathrm{HG}$ nor SA has been tested in an in vivo model of renal IR injury. In vitro assays have demonstrated the accumulation of HIF-1 $\alpha 6$ hours after the administration of $(S)-2 \mathrm{HG}$ to cell cultures (Xu et al. 2011), and the administration of dimethyl fumarate (a structurally related EGLN-inhibitor) has demonstrated a hepatoprotective effect in Wistar at a dose of $25 \mathrm{mg} / \mathrm{kg}$ (Takasu et al. 2017). Hence, we decided to use the following experimental design: 
200

201

202

203

204

205

206

207

208

209

210

211

212

213

214

215

216

217

218

219

220

221

222

223

224

225

226

227

228

229

230

231

232

233

234

235

236

237

Evaluation of treatment with sodium (S)- $2 H G$

Rats were randomized and divided into the following groups.

1. Sham group (SH), $n=6$ : Rats were treated with double-distilled water administered p.o. twice per day for 2 days. They then underwent a laparotomy without induction of kidney IR injury and were allowed to recover for $15 \mathrm{~h}$, after which they were sacrificed, and blood and kidney tissue samples were obtained.

2. Nontoxicity groups, $n=4$ each: Rats were treated with $(S)-2 \mathrm{HG}$ at a dose of 12.5 or 25 $\mathrm{mg} / \mathrm{kg}$ (12.5Tox and 25Tox, respectively) in double-distilled water administered p.o. twice per day for 2 days. Eight hours after the final administration, the rats underwent the same procedure as the $\mathrm{SH}$ group.

3. IR group (IR), $n=6$ : Rats were treated with double-distilled water in the same way as for the SH group. They then underwent a laparotomy and induction of kidney IR injury comprising $45 \mathrm{~min}$ of ischemia and $15 \mathrm{~h}$ of reperfusion. After the reperfusion, the rats were sacrificed, and blood and kidney tissue samples were obtained.

4. IR +12.5 and $\mathrm{IR}+25$ groups, $n=6$ each: Rats were treated with $(S)-2 \mathrm{HG}$ at a dose of 12.5 or $25 \mathrm{mg} / \mathrm{kg}$ in double-distilled water as for the nontoxicity groups. Eight hours after the final administration, rats underwent the same procedure as the IR group.

\section{Evaluation of treatment with $S A$}

Rats were randomized and divided into the following groups.

1. Sham group (SH), $n=6$ : Rats were treated with double-distilled water administered p.o. twice per day for 2 days. They then underwent a laparotomy without induction of kidney IR injury and $15 \mathrm{~h}$ of recovery. The animals were sacrificed, and blood and kidney tissue samples were obtained.

2. Nontoxicity groups, $n=4$ each: Rats were treated with SA at a dose of $12.5,25$, or 50 $\mathrm{mg} / \mathrm{kg}$ (12.5Tox, 25Tox, and 50Tox, respectively) in double-distilled water under the same conditions as the $\mathrm{SH}$ group. Eight hours after treatment, the rats received the same procedure as the $\mathrm{SH}$ group.

3. IR group (IR), $n=6$ : Rats were treated with double-distilled water as for the $\mathrm{SH}$ group. After treatment, they received a laparotomy with induction of kidney IR injury comprising $45 \mathrm{~min}$ of ischemia and $15 \mathrm{~h}$ of reperfusion. After reperfusion, the rats were sacrificed, and blood and kidney tissue samples were obtained.

4. IR $+12.5, \mathrm{IR}+25$, and $\mathrm{IR}+50$ groups, $n=5,6$, or 6 respectively: Rats with treated with SA at a dose of $12.5,25$, or $50 \mathrm{mg} / \mathrm{kg}$ in double-distilled water under the same conditions as for the nontoxicity groups. Eight hours after treatment, rats underwent the same procedure as the IR group.

\section{Induction of kidney IR injury}

The procedure to induce IR injury was based on the protocol of Torres-Gonzalez et al. (TorresGonzález et al. 2018). Rats were anesthetized by intraperitoneal injection with $100 \mathrm{mg} / \mathrm{kg}$ of ketamine (Anesket, PiSA Agropecuaria, S.A. de C.V. Reg. SAGARPA Q7833-028, Guadalajara, Jal., Mexico) and $10 \mathrm{mg} / \mathrm{kg}$ of xylazine (Sedaject, Vedilab S.A. de C.V. Reg. SAGARPA Q0088-122, Querétaro, Qro., Mexico). After anesthesia, rats were shaved, and asepsis of the 
238

239

240

241

242

243

244

245

246

247

248

249

250

251

252

253

254

255

256

257

258

259

260

261

262

263

264

265

266

267

268

269

270

271

272

273

274

275

276

277

abdominal region was performed using Microdacyn antiseptic solution (Oculus Technologies of Mexico, S.A. de C.V., Guadalajara, Jal., Mexico) followed by a 20\% solution of chlorhexidine gluconate (Farmacéuticos Altamirano de México, S.A. de C.V., Mexico City, Mexico). A midline incision was then performed, both kidneys were exposed, the kidneys were dissected at both renal hila, and these structures were occluded using atraumatic vascular clamps for $45 \mathrm{~min}$. After ischemia, the clamps were withdrawn, and the incision was sutured.

Rats were transferred to cages containing UV-sterilized sawdust, and tramadol dissolved in water was administered as an analgesic (50 mg/L, ad libitum) (Grünenthal GmbH, Stolberg, Germany). The reperfusion follow-up occurred over the next $15 \mathrm{~h}$. The rats were then anesthetized by intraperitoneal injection of $50 \mathrm{mg} / \mathrm{kg}$ of ketamine and $5 \mathrm{mg} / \mathrm{kg}$ of xylazine. The incision was reopened, and 5-7 $\mathrm{mL}$ of blood was withdrawn by cava vein phlebotomy, which caused death by exsanguination. When the heart had stopped, both kidneys were removed. Half of each kidney

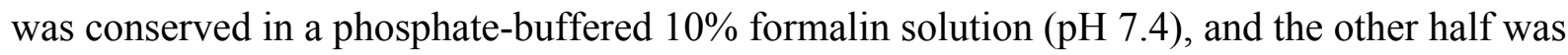
frozen at $-80^{\circ} \mathrm{C}$. Serum was separated from blood samples by centrifugation at $2000 \mathrm{~g}$ for 12 min and stored at $-80^{\circ} \mathrm{C}$ until use.

\section{Analysis of biochemical markers, oxidative stress markers, and proinflammatory cytokines}

To evaluate renal function, the serum concentrations of blood urea nitrogen (BUN) and creatinine were measured. To assess liver function, the serum activities of alanine aminotransferase (ALT), aspartate aminotransferase (AST), lactate dehydrogenase (LDH), and alkaline phosphatase (ALP) were measured. The serum concentrations of glucose (GLU), uric acid (UA), total proteins (TP), and albumin (ALB) were also measured. The biochemical analysis was performed using kinetic or end-point UV-visible spectrophotometric methods in an ILab Aries instrument (Instrumentation Laboratory SpA, Milan, Italy).

To assess the oxidative-stress-induced injury, the tissue concentration of malondialdehyde (MDA), and the tissue activity of total superoxide dismutase (SOD) was measured. Briefly, 200 mg of kidney tissue was homogenized, and the tissue homogenates were centrifuged three times at $10,000 \mathrm{~g}$ for $10 \mathrm{~min}$ at $4^{\circ} \mathrm{C}$. MDA and SOD quantification was performed using the supernatant.

MDA is one of the final products of lipid peroxidation, mainly arachidonic acid, and polyunsaturated fatty acids, and its activity was measured using the thiobarbituric acid colorimetric method with a thiobarbituric acid-reactive substances (TBARS) assay kit (Cayman Chemical Company, Ann Arbor, MI, USA). The product of this reaction was measured spectrophotometrically at $535 \mathrm{~nm}$ and normalized to the amount of homogenized tissue. SOD represents several metalloenzymes that form a crucial part of the cell enzymatic antioxidant defenses. SOD catalyzes the dismutation of the superoxide anion to $\mathrm{O}_{2}$ and $\mathrm{H}_{2} \mathrm{O}_{2}$. Total SOD activity was measured using a method of inhibition of the reduction of Dojindo's water-soluble 
278 tetrazolium salt [WST-1; 2-(4-iodophenyl)-3-(4-nitrophenyl)-5-(2,4-disulfophenyl)-2H

279 tetrazolium, monosodium salt] in the presence of xanthine oxidase, xanthine, and oxygen

280 (Sigma-Aldrich). SOD activity ameliorates the reduction in tetrazolium and was measured

281 spectrophotometrically at $450 \mathrm{~nm}$.

282

283

284

285

286

287

288

The serum concentrations of the proinflammatory cytokines interleukin $1 \beta$ (IL-1 $\beta$ ), IL-6, and tumor necrosis factor- $\alpha$ (TNF- $\alpha$ ) were measured using a commercial sandwich enzyme-linked immunosorbent assay (ELISA) (Pepro-Tech, Mexico City, Mexico). Briefly, 96-well microplates were covered with rabbit antibodies specific to the measured cytokine. Plates were washed with phosphate-buffered saline containing $0.05 \%$ Tween 20 (pH 7.2) and then blocked with 1\% serum bovine albumin. Samples and standards were added and detected using specific biotinylated

290 detection antibodies and avidin-conjugated horseradish peroxidase (HRP). 2,2-Azino-bis(3-

291 ethylbenzothiazoline-6-sulfonic) acid was used as the substrate for HRP; the reaction produced a green chromogen whose concentration was proportional to the concentration of the evaluated

292 cytokine. The concentration of the end-product was measured spectrophotometrically at $405 \mathrm{~nm}$,

293 with an additional $650 \mathrm{~nm}$ wavelength measurement for correction.

294

295

296

\section{Renal histopathology evaluation}

Fixed kidney tissue was paraffin embedded and processed using standard histological techniques.

297

298

299

300

301

302

303

304

305

306

307

308

309

310

311

312

313

314

315

316

Paraffin blocks were cut using a microtome at a thickness of $4 \mu \mathrm{m}$. Sections were deparaffinized, hydrated, stained with hematoxylin-eosin, and evaluated microscopically with the assessor blinded to the identity of the groups.

The presence of tissue damage indicators, such as tubular necrosis, acidophilic casts, and vascular congestion, was assessed. The damage was reported according to the semiquantitative scale published by Kobuchi et al. (Kobuchi et al. 2009) as follows: $0=$ no damage; $1=$ mild damage (unicellular patchy isolated damage); $2=$ moderate damage $(<25 \%) ; 3=$ severe damage $(25-50 \%)$ and $4=$ very severe damage $(>50 \%)$.

\section{Tissue HIF-1 $\alpha$ concentration measurement}

\section{ELISA}

HIF-1 $\alpha$ concentration was assessed in tissue homogenates as described for oxidative stress biomarkers. The analysis was performed using a sandwich ELISA method (Sigma-Aldrich) with specific capture and detection antibodies, the latter conjugated to HRP. 3,3',5,5'-

Tetramethylbenzidine was used as the substrate, and the reaction was stopped by the addition of a $0.2 \mathrm{M}$ solution of $\mathrm{H}_{2} \mathrm{SO}_{4}$. Absorbance was measured at $450 \mathrm{~nm}$. HIF- $1 \alpha$ concentration is reported relative to the amount of homogenate tissue.

\section{Western blot}

PeerJ reviewing PDF | (2020:01:44918:1:1:CHECK 27 May 2020) 
317 HIF-1 $\alpha$ was measured in kidney tissue by a Western blot methodology. Briefly, pools of $100 \mathrm{mg}$ 318 of kidney tissue were mechanically homogenized in $500 \mu \mathrm{L}$ of $1 \mathrm{X}$ lysis buffer containing $10 \mathrm{mM}$ 319 Tris- $\mathrm{HCl}(\mathrm{pH} 7.5) ; 50 \mathrm{mM} \mathrm{KCl}, 2 \mathrm{mM} \mathrm{MgCl} 2,1 \%$ Triton X-100, $1 \mathrm{mM}$ dithiothreitol, $1 \mathrm{mM}$ 320 phenylmethylsulfonyl fluoride and cOmplete ${ }^{\mathrm{TM}}$ Protease Inhibitor Cocktail according to 321 manufacturer conditions (Roche, Basilea, Switzerland) at $4^{\circ} \mathrm{C}$ and centrifuged at $13,000 \mathrm{~g}$ for 5 322 minutes. Proteins were quantified in the supernatant by the Bradford method (Bio-Rad, Hercules, $323 \mathrm{CA}, \mathrm{USA}$ ) and $150 \mu \mathrm{g}$ of protein was separated on $12 \%$ polyacrylamide gels. Proteins were 324 transferred onto PVDF membranes and monoclonal mouse antibodies were used for the detection

325

326 of HIF-1 $\alpha$ (sc-13515; 1:300, $6.7 \mu \mathrm{g} / \mathrm{mL}$, Santa Cruz Biotechnology, Dallas, TX, USA) and

327 GAPDH (MAB5718; 1:10,000; $0.05 \mu \mathrm{g} / \mathrm{mL}$; R\&D Systems, Minneapolis, MN, USA). A secondary HRP-conjugated anti-mouse antibody was used (W4021; 1:10,000;0.1 $\mu \mathrm{g} / \mathrm{mL}$; Promega, Madison, WI, USA), and the signal was measured by chemiluminescence using a Clarity ${ }^{\mathrm{TM}}$ Western ECL Substrate (Bio-Rad).

330

331

332

\section{Quantitative RT-PCR}

333

Total RNA was extracted from $100 \mathrm{mg}$ tissue (pool of both kidneys) using TRIzol reagent

334 (Invitrogen, Thermo Fisher Scientific, Carlsbad, CA, USA) according to the manufacturer's specifications. RNA samples were precipitated with $100 \%$ isopropanol, washed with $75 \%$ ethylalcohol, resuspended in RNase-free water, quantified using a Microdrop Multiskan GO (Thermo Fisher Scientific, Carlsbad, CA, USA) and stored at $-80^{\circ} \mathrm{C}$. RT-qPCR was performed with GoTaq 1-Step (Promega) using as template $100 \mathrm{ng}$ RNA to quantify gene expression levels of Hmox 1 and $\beta$-actin using of following oligonucleotides: Hmox 1 forward 5'-

340 GCCTGCTAGCCTGGTTCAAGA-3', Hmox1 reverse 5'-GAGTGTGAGGACCCATCGCA-3', $\beta$-actin forward 5'-CCCTGGCTCCTAGCACCAT-3' and $\beta$-actin reverse 5'GATAGAGCCACCAATCCACACA-3'. Primers were used at a concentration of $100 \mathrm{nM}$. For each PCR reaction, $10 \mu \mathrm{L}$ of GoTaq qPCR Master Mix 2X, $0.4 \mu \mathrm{L}$ Go Script RT Mix 50X, and $0.33 \mu \mathrm{L}$ CXR Reference Dye were used, to complete a total volume of $20 \mu \mathrm{L}$. Thermal cycling conditions were as follows: reverse transcription one cycle to $37^{\circ} \mathrm{C}$ for 15 minutes, reverse transcription inactivation and Go Taq DNA Polymerase activation one cycle to $95{ }^{\circ} \mathrm{C}$ for 10 minutes, followed by 40 cycles of $95^{\circ} \mathrm{C}$ for 10 seconds and $60^{\circ} \mathrm{C}$ for 30 seconds. $\beta$-actin was used as the housekeeping gene and the fold changes of gene expression were calculated by the $2^{-\Delta \Delta \mathrm{Ct}}$ method.

\section{Statistical analysis}

Data were analyzed using a one-way analysis of variance followed by the Tukey post hoc test or by the Kruskal-Wallis nonparametric test followed by the Dunn post hoc test, depending on the data distribution. Data expressed as fold changes were transformed logarithmically before the statistical analysis. The analysis was performed using GraphPad Prism software (v. 7.0; GraphPad, San Diego, CA, USA). The results are expressed as mean \pm standard deviation (SD). Differences between means were considered to be significant at $p<0.05$. 
357

358

359

360

361

362

363

364

365

366

367

368

369

370

371

372

373

374

375

376

377

378

379

380

381

382

383

384

385

386

387

388

389

390

391

392

393

394

395

396

\section{Results}

\section{Sodium $(S)$-2-HG synthesis and chemical characterization}

(S)-5-Oxotetrahydrofuran-2-carboxylic acid

After chromatographic purification, $1.9012 \mathrm{~g}$ (14.6134 mmol) of (S)-5-oxotetrahydrofuran-2carboxylic acid was obtained at a $73.07 \%$ yield, as a yellow oil, which spontaneously crystallized and produced beige crystals, which were poorly soluble in water but soluble in ethyl acetate, methanol, and ethyl ether.

${ }^{1} \mathrm{H}-\mathrm{NMR}$ (MeOD): $4.994 \mathrm{ppm}(2.8 \mathrm{H}, \mathrm{m}) ; 2.574 \mathrm{ppm}(3 \mathrm{H}, \mathrm{m})$; and $2.296 \mathrm{ppm}(1 \mathrm{H}, \mathrm{m})$. The signal at $4.994 \mathrm{ppm}$ overlapped partially with the signal of the residual water absorbed by the solvent. ${ }^{13} \mathrm{C}-\mathrm{NMR}$ (MeOD): 179.20, 173.58, 77.52, 27.94, and $27.08 \mathrm{ppm}$. Both ${ }^{1} \mathrm{H}$ and ${ }^{13} \mathrm{C}-$ NMR spectra are consistent with the values reported previously (Bal \& Gryff-Keller 2002).

\section{Sodium (S)-2HG}

After precipitation, $882.2 \mathrm{mg}(4.5929 \mathrm{mmol})$ of $(S)-2 \mathrm{HG}$ was obtained at a $31.43 \%$ yield as a beige crystalline solid, which was highly hygroscopic and was soluble in water but insoluble in methanol, ethanol, acetone, ethyl acetate, ethyl ether, or hexane. The global yield of the synthesis of $(S)$-2HG from L-glutamic acid was $22.96 \%$.

In ${ }^{1} \mathrm{H}-\mathrm{NMR}$, the following four signals were observed (Fig. S1): $4.004 \mathrm{ppm}\left(1 \mathrm{H}\right.$, dd; $J^{\prime}=7.6 \mathrm{~Hz}$, $\left.J^{\prime \prime}=4 \mathrm{~Hz}\right) ; 2.223 \mathrm{ppm}(2 \mathrm{H}, \mathrm{m}) ; 1.960 \mathrm{ppm}(1 \mathrm{H}, \mathrm{m})$; and $1.827 \mathrm{ppm}(1 \mathrm{H}, \mathrm{m})$. In ${ }^{13} \mathrm{C}-\mathrm{NMR}$, five signals were observed (Fig. S2): 185.71, 184.10, 75.01, 36.38, and 33.92 ppm. The DEPT-135 experiment showed only three signals: 75.01, 36.38, and 33.92 ppm (Fig. S3). The HSQC (Fig. S4) and HMBC (Fig. S5) experiments allowed the unequivocal signal assignation of the (S)-2HG molecule, which coincided with data reported in the literature (Bal \& Gryff-Keller 2002). (S)$2 \mathrm{HG}$ was obtained with a $98.6 \%$ relative NMR purity.

A value of $[\alpha]_{\mathrm{D}}{ }^{20^{\circ} \mathrm{C}}=-8.40^{\circ} \mathrm{cm}^{3} \mathrm{~g}^{-1} \mathrm{dm}^{-1}$ was observed, which coincides with data previously reported (Ritthausen 1872; Sigma-Aldrich 2018).

\section{Evaluation of the effects of sodium (S)-2HG treatment}

Kidney and liver injury biomarkers

To examine whether $(S)-2 \mathrm{HG}$ had any nephroprotective effects, we compared the SH, 12.5+IR, $25+\mathrm{IR}$, and IR groups. Treatment with $(S)-2 \mathrm{HG}$ produced a dose-dependent decrease in the serum concentrations of BUN and creatinine and increased the TP concentration compared to the IR group. Similarly, it decreased the serum activities of AST, ALP, and LDH compared to the IR group. There were no significant differences between groups in serum concentrations of ALB, GLU, and UA, or the serum activity of ALT (Fig. 2, Table 1, Data S1). 
397 Because one of our aims was to identify any evidence of hepato- or nephrotoxic effects caused 398 by the administration of $(S)-2 \mathrm{HG}$, we compared the nontoxicity and SH groups. There were no 399 significant differences between the 12.5Tox, 25Tox, and SH groups in the serum concentration 400 of BUN or creatinine. The serum concentrations of ALB, GLU, TP, and UA also did not differ 401 between groups. There were no significant differences between the serum activities of ALT; 402 AST; ALP; or LDH (Fig. 2, Table 1, Data S1).

403

404

405

Biomarkers of Oxidative Stress

406

The total \% inhibition rate of WST-1 reduction caused by SOD activity and the normalized tissue MDA concentration did not differ significantly between groups (Table 1).

407

408

409

410

411

412

413

414

415

416

417

418

419

420

421

422

423

424

425

426

427

428

429

430

431

432

433

434

435

436

\section{Proinflammatory Cytokines}

The serum concentrations of IL-1 $\beta$, IL- 6 , and TNF- $\alpha$ did not differ significantly between groups (Table 1).

\section{Evaluation of Renal Histopathology}

Renal histopathology parameters did not differ significantly between the SH, 12.5Tox, and 25Tox groups. The severity of tubular necrosis and the presence of acidophilic casts differed significantly between the IR and SH groups (Table 2, representative microphotographs are shown in Fig. 3).

\section{Evaluation of the effect of sodium (S)-2HG treatment on the tissue HIF-1 $\alpha$ concentration}

To assess whether the nephroprotective effect of $(S)-2 \mathrm{HG}$ was caused by a promotion of the accumulation of HIF-1 $\alpha$, this protein was measured in kidney tissue homogenates. ELISA assessment showed that the normalized HIF- $1 \alpha$ tissue concentration was significantly higher in the 12.5Tox and IR groups compared to the SH group. The normalized HIF-1 $\alpha$ tissue concentration was significantly lower in the $25+$ IR group compared with the IR group. The normalized HIF- $1 \alpha$ tissue concentration did not differ significantly between the 25Tox and 12.5+IR groups compared with the SH and IR groups, respectively (Fig. 4).

Western blot analysis showed no significative differences in the HIF-1 $\alpha$ concentration in the groups Tox12.5 and Tox 25 compared to the SH group. However, a 3.434-fold increase in the concentration of HIF- $1 \alpha$ in the IR group compared to the SH group was observed. On the other hand, the groups $12.5+$ IR and 25+IR showed a significantly lower concentration of HIF-1 $\alpha$ compared to the IR group (Fig. 5).

\section{Evaluation of the effect of sodium (S)-2HG on the expression of Hmoxl in kidney tissue}

The expression of Hmox1 was significantly increased after the treatment with $(S)-2 \mathrm{HG}$ at a dose of $25 \mathrm{mg} / \mathrm{kg}$ (14.15-fold from the SH group). Treatment with a dose of $12.5 \mathrm{mg} / \mathrm{kg}$ did not have a significant effect on its expression (Fig. 6). The induction of IR injury in the IR, 12.5+IR, and 
$43725+$ IR groups drastically increased the expression of Hmox1 compared to the SH group (128.42-

438 fold, 98.94-fold, and 140.01-fold, respectively; Fig. 6).

439

440 Evaluation of the effects of SA treatment

441 Kidney and Liver Injury Biomarkers

442 To identify any nephroprotective effects caused by the administration of SA, we compared the

$443 \mathrm{SH}, 12.5+\mathrm{IR}, 25+\mathrm{IR}$, and 50+IR groups with the IR group. The administration of SA did not

444 decrease BUN compared to the IR group but slightly decreased creatinine concentration in the

$44512.5+$ IR group. There were no significative differences in the creatinine concentrations between

446 the 25+IR and 50+IR compared with the IR group. There was no significant difference between

447 groups in the serum concentrations of ALB, TP, or UA, or in the serum activities of ALT, AST,

448 ALP, or LDH (Fig. 7, Table 3, Data S2).

449

450

451

452

The 12.5Tox, 25Tox, and 50Tox groups were compared with the SH group to identify any hepato- or nephrotoxic effects caused by the administration of SA. There were no significant differences between groups in the serum concentrations of BUN, creatinine, ALB, GLU, TP, or UA. There were also no significant differences between groups in the serum activities of ALT, AST, ALP, or LDH (Fig. 7, Table 3, Data S2).

455

456

Biomarkers of Oxidative Stress

457 The total \% inhibition rate of WST-1 reduction caused by SOD activity and the normalized tissue MDA concentration did not differ significantly between groups (Table 3).

459

460

Proinflammatory Cytokines

461 The serum concentrations of IL-1 $\beta$, IL-6, and TNF- $\alpha$ did not differ significantly between groups 462 (Table 3).

463

464

Evaluation of Renal Histopathology

465

Tubular necrosis was significantly increased in the IR group compared with the SH group. None

466 of the other parameters evaluated differed significantly between groups (Table 4, representative

467 microphotographs are shown in Fig. 8).

468

469

\section{Discussion}

470

Despite improvements in the prevention of immunological graft rejection, few steps have been

471 taken to decrease the magnitude of IR injury. For that reason, strategies are needed to ameliorate

472 the deleterious effects of IR injury. Several mechanisms are involved in the processes causing IR 473 injury, such as ROS generation, redox imbalance, necrosis-apoptosis, and the inflammatory

474 response (Dorweiler et al. 2007). To ameliorate the effects of injury, various strategies have been 475 tried including the use of antioxidants (Li et al. 2014; Torres-González et al. 2018; Yildiz et al. 476 2015), anti-inflammatory compounds (Zhang et al. 2018; Zhu et al. 2014), and surgical 
477 strategies, such as IPC (Cai et al. 2013; Cai et al. 2008; Shen et al. 2018) and RIPC (Albrecht et 478 al. 2013; Hausenloy \& Yellon 2007; Kalakech et al. 2013).

479

480

481

482

483

484

485

486

487

488

489

490

491

492

493

494

495

496

497

498

499

500

501

502

503

504

505

506

507

508

509

510

511

512

513

514

515

516

In this study, we evaluated the ability of pharmacological preconditioning to prevent or reduce the effects of IR injury. Previous studies have demonstrated significant amelioration of IR injury using inhibitors of the EGLN family (Hill et al. 2008; Milkiewicz et al. 2004). Therefore, we evaluated the effects of two structural analogs of $\alpha$-ketoglutarate. $(S)$-2HG was synthesized by a diazotization reaction, followed by alkaline hydrolysis. The diazotization of $\alpha$-amino acids is considered to be a classic reaction for synthesizing $\alpha$-hydroxy acids through the enantioselective route (Brewster et al. 1950; Neuberger 1948; Zollinger 1995) involving a double- $\mathrm{S}_{\mathrm{N}} 2$ mechanism on the $\alpha$ carbon (Markgraf \& Davis 1990; Pleissner et al. 2011; Van Draanen \& Hengst 2010; Zollinger 1995). In this work, we obtained (S)-2HG from L-glutamic acid in a two-step procedure. After the diazotization reaction, the $(S)$-2-hydroxyglutaric lactone was produced; in a second step, the alkaline hydrolysis furnished the desired $(S)-2 \mathrm{HG}$ (Williams et al. 2006). The chemical identity of $(S)-2 \mathrm{HG}$ was established by comparing the experimental NMR spectra and optical activity with those reported in the literature (Bal \& Gryff-Keller 2002). The optical activity of $(S)-2 \mathrm{HG}$ was measured and determined as $[\alpha]_{\mathrm{D}}{ }^{2{ }^{\circ} \mathrm{C}}=-8.40^{\circ} \mathrm{cm}^{3} \mathrm{~g}^{-1} \mathrm{dm}^{-1}$, which is similar to the reported value of $-8.5 \pm 1.5^{\circ} \mathrm{cm}^{3} \mathrm{~g}^{-1} \mathrm{dm}^{-1}$ (Ritthausen 1872; Sigma-Aldrich 2018). These data confirm that the synthetic product was $(S)-2 \mathrm{HG}$.

Several animal models have been used to study renal acute kidney injury caused by IR. Initial studies were performed in animals of relatively large size, such as dogs, pigs, and rabbits, and since the 1960s rat models have been one of the most reported in the literature (Wei \& Dong 2012). However, in recent years, mouse models have become popular mainly due to the availability of standardized genetically engineered strains. Rat models of IR injury have been well characterized (Heyman et al. 2002; Owji et al. 2018), and rats have the advantage of larger anatomical structures and a higher blood volume than mice, yielding larger amounts of serum after exsanguination, making easier to perform a diversity of biochemical assays. Hence, we decided to use a model of renal IR in rats to assess whether $(S)-2 \mathrm{HG}$ and SA exert a nephroprotective effect.

The length of the periods of ischemia and reperfusion is a major variable to consider in renal IR models. Several studies have reported a broad range of IR conditions. Periods of ischemia of 45 minutes (Kang et al. 2005) and 60 minutes (Nakagawa et al. 2005) have been widely reported in the literature. We decided to use a protocol of 45 minutes of ischemia and 15 hours of reperfusion based on the results of previous studies in our laboratory, which have shown that this protocol causes a significative injury, but is mild enough to identify compounds with moderate nephroprotective activity, allowing us to study deeply their potential pharmacologic activity (Cura-Esquivel et al. 2018; Perez-Meseguer et al. 2019; Torres-González et al. 2018).

Peer] reviewing PDF | (2020:01:44918:1:1:CHECK 27 May 2020) 
517 It has been widely demonstrated that susceptibility to IR injury is gender-dependent. Studies both 518 in mice and rats have shown that the estradiol-androgen ratio has a key role in the modulation of

519 IR injury. High concentrations of testosterone are associated with a more aggressive injury and 520 higher mortality (Robert et al. 2011), and orchiectomy has been shown to attenuate the post521 ischemic oxidative stress and the IR injury in mice (Kim et al. 2006). We decided to use male 522 and female rats because of the availability of animals in our laboratory. For that reason, the use 523 of independent SH and IR control groups was imperative. The fact that we did not assess each 524 compound both in male and female rats is a limitation of this study. Additional experiments are

525

526

527

528

529

530

531

532

533

534

535

536

537

538

539

540

541

542

543

544

545

546

547

548

549

550

551

552

553

554

555

556 needed to demonstrate the effect of these compounds on both genders.

Metabolism of $(S)$-2HG has not been well characterized in animal models. Biochemical studies have reported an $(S)-2 \mathrm{HG}$ dehydrogenase activity of $4.5 \pm 5.5 \mathrm{nmol} / \mathrm{min} / \mathrm{mg}$ of protein in rat liver, significantly higher than the activity in the kidney (less than $1 \mathrm{nmol} / \mathrm{min} / \mathrm{mg}$ of protein) and other organs (Jansen \& Wanders 1993), but pharmacokinetic experiments are still needed. Studies assessing the chronic exposure to $(S)$-2HG have not been performed, however, the chronic exposure to the $(R)-2 \mathrm{HG}$ enantiomer has already been reported. A study showed that the daily injection of a dose of $250 \mathrm{mg} / \mathrm{kg}$ for 32 days caused significant skeletal atrophy and a decrease of the body weight in mice (Karlstaedt et al. 2016). Nevertheless, these results cannot be extrapolated to our model, because of the different effects produced by each of the enantiomers of 2-HG in vitro (Koivunen et al. 2012). Besides, the application of EGLN inhibitors in the field of solid organ transplantation does not require the use of a chronic exposition, but just an acute administration of the drug. In our study, $(S)-2 \mathrm{HG}$ caused no toxic effects at the hepatic or renal level at the evaluated doses in our experimental conditions, as shown by the normal values of the biochemical markers. Comparison between the nontoxicity groups and the SH group showed no effects of $(S)-2 \mathrm{HG}$ on the biomarkers of oxidative stress, proinflammatory cytokines, and histological parameters. By contrast, $(S)-2 \mathrm{HG}$ exerted a dosedependent nephroprotective effect in the groups that underwent IR injury, as manifested by the significant amelioration of the changes in the serum concentrations of BUN and creatinine after IR injury. IR injury caused an increase of the serum ALP, AST, and LDH activities, whereas $(S)$ $2 \mathrm{HG}$ caused a significant amelioration of the activity of these enzymes, which suggests a protective effect of this compound. The TP concentrations differed significantly between the IR and $25+$ IR groups, although these values were within the reported reference interval for this rat strain (Boehm et al. 2007).

Oxidative stress is one of the main mechanisms involved in IR injury. However, we observed no changes in the biomarkers of oxidative stress after IR injury in our rat model. The magnitude of MDA production and the decrease in tissue SOD activity after IR injury depends on the duration of ischemia and reperfusion. Our results are consistent with those reported previously showing that these changes are nonsignificant after $30 \mathrm{~min}$ of ischemia and $24 \mathrm{~h}$ of reperfusion (Dobashi et al. 2000). 
557

558

559

560

561

562

563

564

565

566

567

568

569

570

571

572

573

574

575

576

577

578

579

580

581

582

583

584

585

586

587

588

589

590

591

592

593

594

595

596

The role of the inflammatory response in the renal IR mechanism is well known and involves the promotion of IL-1 production, which stimulates tubular cells to produce IL-6 and TNF- $\alpha$ (Daha $\&$ van Kooten 2000). However, reports are inconsistent. One study noted that IR does not increase the concentrations of these cytokines (Zhu et al. 2014), whereas other studies have reported increases in cytokine concentrations in proportion to the severity of injury (Shen et al. 2018; Tang et al. 2017; Zhang et al. 2018; Zhang et al. 2015). In this work, we did not observe significant increases in the concentrations of IL-1 $\beta$, IL-6, or TNF- $\alpha$. We also found that $(S)-2 \mathrm{HG}$ did not decrease the concentrations of these proinflammatory cytokines compared with their baseline levels, which suggests that the compound has no immunomodulatory effect. HIF-1 $\alpha$ promoted the expression of proinflammatory cytokines such as IL-1 $\alpha$ (Rider et al. 2012) and IL$1 \beta$ (Ogryzko et al. 2019; Zhang et al. 2006) in several experimental models. Because these cytokines stimulate the production of IL- 6 and TNF- $\alpha$, it is possible that this effect antagonizes the potential amelioration of the inflammatory response induced by the nephroprotective effect of $(S)$-2HG. Additional studies are required to confirm this idea.

Renal IR caused significant injury to tissue architecture, which appears as acute tubular necrosis. We observed a tendency for $(S)-2 \mathrm{HG}$ toward amelioration of tissue injury in the three histological parameters evaluated, but these changes were not statistically significant. These results agree with those of other studies of compounds with nephroprotective activity, in which the magnitude of tissue injury was assessed using a semiquantitative approach (Kobuchi et al. 2009; Torres-González et al. 2018). The use of morphometric analysis would have allowed us to quantify the ratio of damaged to undamaged renal tubules and to use parametric statistic tests, as reported previously (Barrera-Chimal et al. 2011), to examine this question at the tissue level.

\section{$(S)-2 \mathrm{HG}$ administration did not exert an unequivocal accumulation of HIF-1 $\alpha$ in the} experimental conditions used in our study, as it was shown by the measurements performed in kidney tissue by ELISA and Western blot. It has been shown that the administration of EGLN inhibitors 6-8 h before ischemia causes HIF-1 $\alpha$ accumulation (Bernhardt et al. 2009; Xu et al. 2011). In the present study, IR injury was induced $8 \mathrm{~h}$ after the final dose of $(S)-2 \mathrm{HG}$ and tissue HIF-1 $\alpha$ concentration was measured $15 \mathrm{~h}$ after IR injury. HIF-1 $\alpha$ is a highly regulated protein, extremely sensitive to the concentration of $\mathrm{O}_{2}$ in the microenvironment and easily degraded (in this study we observed a semi-degraded $55 \mathrm{kDa}$ isoform of HIF-1 $\alpha$ in the Western blot, as referred by several manufacturers of anti-HIF-1 $\alpha$ antibodies). For that reason, it is understandable that the expression of this protein would not be stable after the long reperfusion period; however, the IR group showed a significant accumulation of HIF-1 $\alpha$ after the 15-hours reperfusion period, but the $12.5+\mathrm{IR}$ and $25+\mathrm{IR}$ groups did not follow this behavior. The effect observed in the IR group is consistent with that of a study in which HIF-1 $\alpha$ accumulation caused by IR occurred in two phases, namely an acute phase during ischemia and a late phase during reperfusion (Conde et al. 2012). The findings of the present study suggest that the activation of a

Peer] reviewing PDF | (2020:01:44918:1:1:CHECK 27 May 2020) 
597 nephroprotective mechanism by the treatment with $(S)-2 \mathrm{HG}$ could be related whit the non-

598

599

600

601

602

603

604

605

606

607

608

609

610

611

612

613

614

615

616

617

618

619

620

621

622

623

624

625

626

627

628

629

630

631

632

633

634

635

636

accumulation of HIF-1 $\alpha$ during the late reperfusion period in the treated groups. Differences in the patterns of HIF- $1 \alpha$ expression measured by ELISA or Western blot could be explained based on the instability of HIF-1 $\alpha$. Different sample treatments resulted in distinct grades of degradation, requiring additional experiments to comprehensively assess the effect of sample preparation in the HIF- $1 \alpha$ concentrations.

Despite the inherent instability of HIF-1 $\alpha$ in these experimental conditions, the expression of genes directly transcribed by HIF-1 is an indirect way to infer a previous stabilization of HIF-1 $\alpha$ caused by the administration of (S)-2HG. Inducible heme oxygenase (heme oxygenase 1, Hmox1) is a microsomal membrane enzyme, which catalyzes the oxidative cleavage of heme molecules, yielding biliverdin, $\mathrm{CO}$ and iron. The expression of this enzyme increases significatively in response to hypoxia (it is hypothesized that biliverdin exerts an antioxidant effect, antagonistic to the heme-mediated production of ROS), and it is regulated directly by HIF-1 (Lee et al. 1997). It has been described that the inhibition of the EGLN family induces a 45 fold increase in the Hmox 1 expression in a model of kidney transplantation in rats and that the expression of this gene is stable for at least 24 hours after the inhibition of the EGLN family (Bernhardt et al. 2009). In this study, we observed a 14-fold increase in the expression of Hmox 1 in the Tox 25 group compared to the SH group. This significant increase in the expression of Hmox 1 strongly suggests a role of the HIF-1 pathway in the nephroprotective effect showed by the $(S)-2 \mathrm{HG}$. It has been described that the IR injury induces per se the expression of Hmox 1 in rats and that the transcript is also stable for at least 24 hours (Maines et al. 1993). In this study, we observed that IR injury drastically increased the expression of Hmox 1 in the IR, 12.5+IR, and $25+$ IR groups, with a tendency to increase its expression in the 25+IR group. Additional studies are needed to fully characterize the biochemical pathways modified by $(S)-2 \mathrm{HG}$ in the IR injury, in the kidney, and in other organs.

By contrast, we observed no toxic effects of SA at the hepatic or renal level at the doses used, as shown by the normal biomarker values, which agrees with the findings of Maekawa et al. who reported the absence of a toxic effect in rats of the F344 strain (Maekawa et al. 1990). In our study, it was not observed an alteration in the proinflammatory cytokines, the oxidative stress biomarkers, or the histological parameters.

Unlike (S)-2HG, which showed a significant nephroprotective effect, SA tended to aggravate IR injury, as shown by the inability to ameliorate the changes in BUN and creatinine concentrations at most of the doses used, although there was a trend toward a dose-dependent effect. We found no changes in the other biomarkers evaluated after SA administration. The role of SA in the IR injury processes has been extensively investigated. SA accumulates significantly during the IR injury processes, such as in brain stroke, and its intracellular concentration can increase by up to 30-fold (Chouchani et al. 2014; Sahni et al. 2017). SA plays a role in the reverse electron

Peerj reviewing PDF | (2020:01:44918:1:1:CHECK 27 May 2020) 
637 transport (RET) phenomenon (Scialò et al. 2017), which occurs in the inner mitochondrial 638 membrane when complexes III and IV of the electron transport chain are saturated and RET 639 occurs in complex I and ROS are generated (Chouchani et al. 2014). Stimulation of complex II 640 (succinate dehydrogenase) strongly promotes the RET phenomenon (Chance \& Hollunger 1961), 641 and it is probable that SA administration before IR induction activates this mechanism and

642 produces large amounts of ROS. Additionally, an in vitro study has demonstrated that, despite its 643 EGLN-1 inhibitory activity, SA cannot cause intracellular HIF-1 $\alpha$ accumulation (Koivunen et al. 644 2007).

645

646 SA did not affect the biomarkers of oxidative stress or proinflammatory cytokines. Additional 647 studies under different IR conditions are needed to examine the behavior of these mediators in 648 response to this compound. Histological analysis of the SA-treated groups showed a dose649 dependent tendency toward increased histological evidence of injury. Although this response was 650 not statistically significant, it is possible that the effect was underestimated by the nonparametric 651 test used to analyze the semiquantitative data. Further quantitative morphometric studies are 652 needed to confirm whether SA affects tissue architecture in association with IR injury.

653

654 As previously described, inhibitors of the EGLN family, such as dimethyloxalylglycine and L655 mimosine, promote tissue HIF- $1 \alpha$ accumulation and significantly ameliorate the changes in 656 serum BUN and creatinine levels and histological damage after IR injury (Hill et al. 2008). 657 Similarly, the administration of the EGLN inhibitor FG-4497 has been shown to improve graft 658 survival in an allogenic kidney transplantation model (Bernhardt et al. 2009). The results of our 659 study suggest that $(S)-2 \mathrm{HG}$ is a potential candidate for additional studies in animal models. The 660 effects caused by SA administration are similar to those reported for mitochondrial ROS 661 production by RET. Therefore, subsequent evaluation of this compound in other IR models may

662 help to elucidate the mechanisms underlying these metabolic pathways, as well as the possible 663 clinical implications.

664

\section{Conclusions}

666 Neither $(S)-2 \mathrm{HG}$ nor SA showed a hepato- or nephrotoxic effect at the doses tested. $(S)-2 \mathrm{HG}$

667 showed a dose-dependent nephroprotective effect against IR injury, which involved amelioration 668 of kidney injury biomarkers and an increase in the expression of Hmox 1, suggesting stabilization 669 of HIF-1 $\alpha$. SA did not show a nephroprotective effect but tended to increase IR injury when 670 given at high doses. Neither $(S)$-2HG nor SA exhibited immunomodulatory or antioxidant 671 activity at the different doses used here.

672

\section{References}

674 Albrecht M, Zitta K, Bein B, Wennemuth G, Broch O, Renner J, Schuett T, Lauer F, Maahs D, 675 Hummitzsch L, Cremer J, Zacharowski K, and Meybohm P. 2013. Remote ischemic 
676

677

678

679

680

681

682

683

684

685

686

687

688

689

690

691

692

693

694

695

696

697

698

699

700

701

702

703

704

preconditioning regulates HIF-1alpha levels, apoptosis and inflammation in heart tissue of cardiosurgical patients: a pilot experimental study. Basic Research in Cardiology 108:314. 10.1007/s00395-012-0314-0

Appelhoff RJ, Tian Y-M, Raval RR, Turley H, Harris AL, Pugh CW, Ratcliffe PJ, and Gleadle JM. 2004. Differential Function of the Prolyl Hydroxylases PHD1, PHD2, and PHD3 in the Regulation of Hypoxia-inducible Factor. Journal of Biological Chemistry 279:3845838465. 10.1074/jbc.M406026200

Bal D, and Gryff-Keller A. 2002. 1H and 13C NMR study of 2-hydroxyglutaric acid and its lactone. Magnetic Resonance in Chemistry 40:533-536. 10.1002/mrc.1053

Barrera-Chimal J, Pérez-Villalva R, Cortés-González C, Ojeda-Cervantes M, Gamba G, Morales-Buenrostro LE, and Bobadilla NA. 2011. Hsp72 is an early and sensitive biomarker to detect acute kidney injury. EMBO molecular medicine 3:5-20. 10.1002/emmm.201000105

Bauer T, and Gajewiak J. 2004. $\alpha$-Hydroxy carboxylic acids as ligands for enantioselective diethylzinc additions to aromatic and aliphatic aldehydes. Tetrahedron 60:9163-9170. 10.1016/j.tet.2004.07.060

Bernhardt WM, Gottmann U, Doyon F, Buchholz B, Campean V, Schödel J, Reisenbuechler A, Klaus S, Arend M, Flippin L, Willam C, Wiesener MS, Yard B, Warnecke C, and Eckardt K-U. 2009. Donor treatment with a PHD-inhibitor activating HIFs prevents graft injury and prolongs survival in an allogenic kidney transplant model. Proceedings of the National Academy of Sciences 106:21276-21281. 10.1073/pnas.0903978106

Boehm O, Zur B, Koch A, Tran N, Freyenhagen R, Hartmann M, and Zacharowski K. 2007. Clinical chemistry reference database for Wistar rats and C57/BL6 mice. Biol Chem 388:547-554. 10.1515/bc.2007.061

Brewster P, Hiron F, Hughes ED, Ingold CK, and Rao PADS. 1950. Configuration of Carbohydrates, Hydroxy-Acids and Amino-Acids: Configurations of Amino-Compounds and the Steric Course of Deamination. Nature 166:179-180. 10.1038/166179a0

Bruick RK, and McKnight SL. 2001. A Conserved Family of Prolyl-4-Hydroxylases That Modify HIF. Science 294:1337-1340. 10.1126/science.1066373

Peer) reviewing PDF | (2020:01:44918:1:1:CHECK 27 May 2020) 
705

706

707

708

709

710

711

712

713

714

715

716

717

718

719

720

721

722

723

724

725

726

727

728

729

730

731

732

733

734

735

Cai Z, Luo W, Zhan H, and Semenza GL. 2013. Hypoxia-inducible factor 1 is required for remote ischemic preconditioning of the heart. Proceedings of the National Academy of Sciences 110:17462-17467. 10.1073/pnas.1317158110

Cai Z, Zhong H, Bosch-Marce M, Fox-Talbot K, Wang L, Wei C, Trush MA, and Semenza GL. 2008. Complete loss of ischaemic preconditioning-induced cardioprotection in mice with partial deficiency of HIF-1 $\alpha$. Cardiovascular Research 77:463-470. 10.1093/cvr/cvm035

CENATRA. 2018. Reporte Anual 2018 de Donación y Trasplantes en México. México: Centro Nacional de Trasplantes.

Chance B, and Hollunger G. 1961. The Interaction of Energy and Electron Transfer Reactions in Mitochondria: I. GENERAL PROPERTIES AND NATURE OF THE PRODUCTS OF SUCCINATE-LINKED REDUCTION OF PYRIDINE NUCLEOTIDE. $J$ Biol Chem 236:1534-1543.

Chen F, and Date H. 2015. Update on ischemia-reperfusion injury in lung transplantation. Current opinion in organ transplantation 20:515-520. 10.1097/MOT.0000000000000234 Chouchani ET, Pell VR, Gaude E, Aksentijević D, Sundier SY, Robb EL, Logan A, Nadtochiy SM, Ord ENJ, Smith AC, Eyassu F, Shirley R, Hu C-H, Dare AJ, James AM, Rogatti S, Hartley RC, Eaton S, Costa ASH, Brookes PS, Davidson SM, Duchen MR, Saeb-Parsy K, Shattock MJ, Robinson AJ, Work LM, Frezza C, Krieg T, and Murphy MP. 2014. Ischaemic accumulation of succinate controls reperfusion injury through mitochondrial ROS. Nature 515:431. 10.1038/nature13909

Conde E, Alegre L, Blanco-Sánchez I, Sáenz-Morales D, Aguado-Fraile E, Ponte B, Ramos E, Sáiz A, Jiménez C, Ordoñez A, López-Cabrera M, del Peso L, de Landázuri MO, Liaño F, Selgas R, Sanchez-Tomero JA, and García-Bermejo ML. 2012. Hypoxia inducible factor 1-alpha (HIF-1 alpha) is induced during reperfusion after renal ischemia and is critical for proximal tubule cell survival. PLoS One 7:e33258-e33258. 10.1371/journal.pone.0033258

Cura-Esquivel I, Delgado-Chávez EN, García-Narro JH, Torres-González L, Alarcón-Galván G, Moreno-Peña DP, Esquivel-Figueroa D, Cantú-Machuca DV, Muñoz- Espinosa LE, Garza-Ocañas L, and Cordero-Pérez P. 2018. Attenuation of pro-inflammatory cytokines and oxidative stress by misoprostol in renal ischemia/reperfusion in rats. Die Pharmazie An International Journal of Pharmaceutical Sciences 73:537-540. 10.1691/ph.2018/8498 
736 Daha MR, and van Kooten C. 2000. Is the proximal tubular cell a proinflammatory cell?

737

738

739

740

741

742

743

744

745

746

747

748

749

750

751

752

753

754

755

756

757

758

759

760

761

762

763

764

765 Nephrology Dialysis Transplantation 15:41-43.10.1093/ndt/15.suppl_6.41

Dang L, White DW, Gross S, Bennett BD, Bittinger MA, Driggers EM, Fantin VR, Jang HG, Jin S, Keenan MC, Marks KM, Prins RM, Ward PS, Yen KE, Liau LM, Rabinowitz JD, Cantley LC, Thompson CB, Vander Heiden MG, and Su SM. 2009. Cancer-associated IDH1 mutations produce 2-hydroxyglutarate. Nature 462:739-744. 10.1038/nature08617

Dengler VL, Galbraith MD, and Espinosa JM. 2014. Transcriptional regulation by hypoxia inducible factors. Critical Reviews in Biochemistry and Molecular Biology 49:1-15. $10.3109 / 10409238.2013 .838205$

Dobashi K, Ghosh B, Orak JK, Singh I, and Singh AK. 2000. Kidney ischemia-reperfusion: Modulation of antioxidant defenses. Molecular and Cellular Biochemistry 205:1-11. 10.1023/a:1007047505107

Dorweiler B, Pruefer D, Andrasi TB, Maksan SM, Schmiedt W, Neufang A, and Vahl CF. 2007. Ischemia-reperfusion injury. European Journal of Trauma and Emergency Surgery $33: 600-612.10 .1007 / \mathrm{s} 00068-007-7152-\mathrm{z}$

Granger DN. 1988. Role of xanthine oxidase and granulocytes in ischemia-reperfusion injury. American Journal of Physiology-Heart and Circulatory Physiology 255:H1269-H1275. 10.1152/ajpheart.1988.255.6.H1269

Hausenloy DJ, and Yellon DM. 2007. Reperfusion injury salvage kinase signalling: taking a RISK for cardioprotection. Heart Fail Rev 12:217-234. 10.1007/s10741-007-9026-1

Heyman SN, Lieberthal W, Rogiers P, and Bonventre JV. 2002. Animal models of acute tubular necrosis. Current Opinion in Critical Care 8:526-534.

Hill P, Shukla D, Tran MGB, Aragones J, Cook HT, Carmeliet P, and Maxwell PH. 2008. Inhibition of Hypoxia Inducible Factor Hydroxylases Protects Against Renal IschemiaReperfusion Injury. Journal of the American Society of Nephrology 19:39-46. 10.1681/asn.2006090998

Ivan M, Kondo K, Yang H, Kim W, Valiando J, Ohh M, Salic A, Asara JM, Lane WS, and Kaelin Jr. WG. 2001. HIF $\alpha$ Targeted for VHL-Mediated Destruction by Proline Hydroxylation: Implications for O2 Sensing. Science 292:464-468. 10.1126/science. 1059817 
766

767

768

769

770

771

772

773

774

775

776

777

778

779

780

781

782

783

784

785

786

787

788

789

790

791

792

793

794 795

Jaakkola P, Mole DR, Tian Y-M, Wilson MI, Gielbert J, Gaskell SJ, Kriegsheim Av, Hebestreit HF, Mukherji M, Schofield CJ, Maxwell PH, Pugh CW, and Ratcliffe PJ. 2001. Targeting of HIF- $\alpha$ to the von Hippel-Lindau Ubiquitylation Complex by O2-Regulated Prolyl Hydroxylation. Science 292:468-472. 10.1126/science.1059796

Jansen GA, and Wanders RJA. 1993. 1-2-Hydroxyglutarate dehydrogenase: identification of a novel enzyme activity in rat and human liver. Implications for 1-2-hydroxyglutaric acidemia. Biochimica et Biophysica Acta (BBA) - Molecular Basis of Disease 1225:5356. https://doi.org/10.1016/0925-4439(93)90121-G

Kaelin WG, and Ratcliffe PJ. 2008. Oxygen Sensing by Metazoans: The Central Role of the HIF Hydroxylase Pathway. Molecular Cell 30:393-402. 10.1016/j.molcel.2008.04.009

Kalakech H, Tamareille S, Pons S, Godin-Ribuot D, Carmeliet P, Furber A, Martin V, Berdeaux A, Ghaleh B, and Prunier F. 2013. Role of hypoxia inducible factor-1 $\alpha$ in remote limb ischemic preconditioning. J Mol Cell Cardiol 65:98-104. 10.1016/j.yjmcc.2013.10.001

Kang DG, Sohn EJ, Moon MK, Lee YM, and Lee HS. 2005. Rehmannia glutinose Ameliorates Renal Function in the Ischemia/Reperfusion-Induced Acute Renal Failure Rats. Biological and Pharmaceutical Bulletin 28:1662-1667. 10.1248/bpb.28.1662

Karlstaedt A, Zhang X, Vitrac H, Harmancey R, Vasquez H, Wang JH, Goodell MA, and Taegtmeyer H. 2016. Oncometabolite D-2-hydroxyglutarate impairs $\alpha$-ketoglutarate dehydrogenase and contractile function in rodent heart. Proceedings of the National Academy of Sciences 113:10436-10441. 10.1073/pnas.1601650113 \%J Proceedings of the National Academy of Sciences

Karuppagounder SS, and Ratan RR. 2012. Hypoxia-Inducible Factor Prolyl Hydroxylase Inhibition: Robust New Target or Another Big Bust for Stroke Therapeutics? Journal of Cerebral Blood Flow \& Metabolism 32:1347-1361. 10.1038/jcbfm.2012.28

Kim J, Kil IS, Seok YM, Yang ES, Kim DK, Lim DG, Park J-W, Bonventre JV, and Park KM. 2006. Orchiectomy Attenuates Post-ischemic Oxidative Stress and Ischemia/Reperfusion Injury in Mice: A ROLE FOR MANGANESE SUPEROXIDE DISMUTASE. Journal of Biological Chemistry 281:20349-20356. 10.1074/jbc.M512740200

Kobuchi S, Shintani T, Sugiura T, Tanaka R, Suzuki R, Tsutsui H, Fujii T, Ohkita M, Ayajiki K, and Matsumura Y. 2009. Renoprotective effects of gamma-aminobutyric acid on 
796

797

798

799

800

801

802

803

804

805

806

807

808

809

810

811

812

813

814

815

816

817

818

819

820

821

822

823

824

ischemia/reperfusion-induced renal injury in rats. European Journal of Pharmacology 623:113-118. 10.1016/j.ejphar.2009.09.023

Koivunen P, Hirsilä M, Remes AM, Hassinen IE, Kivirikko KI, and Myllyharju J. 2007. Inhibition of Hypoxia-inducible Factor (HIF) Hydroxylases by Citric Acid Cycle Intermediates: POSSIBLE LINKS BETWEEN CELL METABOLISM AND STABILIZATION OF HIF. J Biol Chem 282:4524-4532. 10.1074/jbc.M610415200

Koivunen P, Lee S, Duncan CG, Lopez G, Lu G, Ramkissoon S, Losman JA, Joensuu P, Bergmann U, Gross S, Travins J, Weiss S, Looper R, Ligon KL, Verhaak RGW, Yan H, and Kaelin Jr WG. 2012. Transformation by the (R)-enantiomer of 2-hydroxyglutarate linked to EGLN activation. Nature 483:484-488. 10.1038/nature10898

Kolitz M, Cohen-Arazi N, Hagag I, Katzhendler J, and Domb AJ. 2009. Biodegradable Polyesters Derived from Amino Acids. Macromolecules 42:4520-4530. $10.1021 / \mathrm{ma900464g}$

Lee PJ, Jiang B-H, Chin BY, Iyer NV, Alam J, Semenza GL, and Choi AMK. 1997. Hypoxiainducible Factor-1 Mediates Transcriptional Activation of the Heme Oxygenase-1 Gene in Response to Hypoxia. Journal of Biological Chemistry 272:5375-5381. $10.1074 /$ jbc. 272.9 .5375

Li YW, Zhang Y, Zhang L, Li X, Yu JB, Zhang HT, Tan BB, Jiang LH, Wang YX, Liang Y, Zhang XS, Wang WS, and Liu HG. 2014. Protective effect of tea polyphenols on renal ischemia/reperfusion injury via suppressing the activation of TLR4/NF-kappaB p65 signal pathway. Gene 542:46-51. 10.1016/j.gene.2014.03.021

Maekawa A, Todate A, Onodera H, Matsushima Y, Nagaoka T, Shibutani M, Ogasawara H, Kodama Y, and Hayashi Y. 1990. Lack of toxicity/carcinogenicity of monosodium succinate in F344 rats. Food and Chemical Toxicology 28:235-241. 10.1016/02786915(90)90035-L

Maines MD, Mayer RD, Ewing JF, and McCoubrey WK. 1993. Induction of kidney heme oxygenase-1 (HSP32) mRNA and protein by ischemia/reperfusion: possible role of heme as both promotor of tissue damage and regulator of HSP32. Journal of Pharmacology and Experimental Therapeutics 264:457-462. 
825 Markgraf JH, and Davis HA. 1990. Steric course of lactonization in the deamination of glutamic

826

827

828

829

830

831

832

833

834

835

836

837

838

839

840

841

842

843

844

845

846

847

848

849

850

851

852

853

854

855

acid: An organic mechanism experiment. Journal of Chemical Education 67:173. $10.1021 /$ ed067p173

McManaman JL, and Bain DL. 2002. Structural and Conformational Analysis of the Oxidase to Dehydrogenase Conversion of Xanthine Oxidoreductase. Journal of Biological Chemistry 277:21261-21268. 10.1074/jbc.M200828200

Milkiewicz M, Pugh CW, and Egginton S. 2004. Inhibition of endogenous HIF inactivation induces angiogenesis in ischaemic skeletal muscles of mice. The Journal of Physiology 560:21-26. 10.1113/jphysiol.2004.069757

Murry CE, Jennings RB, and Reimer KA. 1986. Preconditioning with ischemia: a delay of lethal cell injury in ischemic myocardium. Circulation 74:1124-1136.

$$
\text { 10.1161/01.CIR.74.5.1124 }
$$

Myllyharju J. 2009. HIF prolyl 4-hydroxylases and their potential as drug targets. Curr Pharm Des 15:3878-3885. 10.2174/138161209789649457

Nakagawa T, Yokozawa T, Satoh A, and Kim HY. 2005. Attenuation of Renal IschemiaReperfusion Injury by Proanthocyanidin-Rich Extract from Grape Seeds. Journal of Nutritional Science and Vitaminology 51:283-286. 10.3177/jnsv.51.283

Neuberger A. 1948. Stereochemistry of Amino Acids. Advances in Protein Chemistry 4:297-383. 10.1016/S0065-3233(08)60009-1

Ogryzko NV, Lewis A, Wilson HL, Meijer AH, Renshaw SA, and Elks PM. 2019. Hif-1 $\alpha-$ Induced Expression of Il-1 $\beta$ Protects against Mycobacterial Infection in Zebrafish. The Journal of Immunology 202:494. 10.4049/jimmunol.1801139

Ohh M, Park CW, Ivan M, Hoffman MA, Kim T-Y, Huang LE, Pavletich N, Chau V, and Kaelin WG. 2000. Ubiquitination of hypoxia-inducible factor requires direct binding to the $\beta$ domain of the von Hippel-Lindau protein. Nature Cell Biology 2:423-427. $10.1038 / 35017054$

Owji SM, Nikeghbal E, and Moosavi SM. 2018. Comparison of ischaemia-reperfusion-induced acute kidney injury by clamping renal arteries, veins or pedicles in anaesthetized rats. Experimental Physiology 103:1390-1402. 10.1113/ep087140

Pauli GF, Jaki BU, and Lankin DC. 2007. A Routine Experimental Protocol for qHNMR Illustrated with Taxol. Journal of Natural Products 70:589-595. 10.1021/np060535r 
856 Perez-Meseguer J, Torres-González L, Gutiérrez-González JA, Alarcón-Galván G, Zapata-

857

858

859

860

861

862

863

864

865

866

867

868

869

870

871

872

873

874

875

876

877

878

879

880

881

882

883

884 Chavira H, Waksman-de Torres N, Moreno-Peña DP, Muñoz-Espinosa LE, and CorderoPérez P. 2019. Anti-inflammatory and nephroprotective activity of Juglans mollis against renal ischemia-reperfusion damage in a Wistar rat model. BMC Complementary and Alternative Medicine 19:186. 10.1186/s12906-019-2604-7

Pleissner D, Wimmer R, and Eriksen NT. 2011. Quantification of Amino Acids in Fermentation Media by Isocratic HPLC Analysis of Their $\alpha$-Hydroxy Acid Derivatives. Analytical Chemistry 83:175-181. 10.1021/ac1021908

Przyklenk K, Bauer B, Ovize M, Kloner RA, and Whittaker P. 1993. Regional ischemic 'preconditioning' protects remote virgin myocardium from subsequent sustained coronary occlusion. Circulation 87:893-899. 10.1161/01.CIR.87.3.893

Randhawa PK, Bali A, and Jaggi AS. 2015. RIPC for multiorgan salvage in clinical settings: Evolution of concept, evidences and mechanisms. European Journal of Pharmacology 746:317-332. 10.1016/j.ejphar.2014.08.016

Rider P, Kaplanov I, Romzova M, Bernardis L, Braiman A, Voronov E, and Apte R. 2012. The transcription of the alarmin cytokine interleukin-1 alpha is controlled by hypoxia inducible factors 1 and 2 alpha in hypoxic cells. Frontiers in Immunology 3. 10.3389/fimmu.2012.00290

Ritthausen H. 1872. Ueber das Drehungsvermögen von Glutan- und Aepfelsäure. Journal für Praktische Chemie 5:354-355. doi:10.1002/prac.18720050132

Robert R, Ghazali DA, Favreau F, Mauco G, Hauet T, and Goujon J-M. 2011. Gender difference and sex hormone production in rodent renal ischemia reperfusion injury and repair. Journal of Inflammation 8:14. 10.1186/1476-9255-8-14

Sahni PV, Zhang J, Sosunov S, Galkin A, Niatsetskaya Z, Starkov A, Brookes PS, and Ten VS. 2017. Krebs cycle metabolites and preferential succinate oxidation following neonatal hypoxic-ischemic brain injury in mice. Pediatr Res 83:491. 10.1038/pr.2017.277

Salvadori M, Rosso G, and Bertoni E. 2015. Update on ischemia-reperfusion injury in kidney transplantation: Pathogenesis and treatment. World journal of transplantation 5:52. $10.5500 \% 2 F w j t . v 5.12 .52$ 
885 Scialò F, Fernández-Ayala DJ, and Sanz A. 2017. Role of Mitochondrial Reverse Electron 886 Transport in ROS Signaling: Potential Roles in Health and Disease. Frontiers in 887 Physiology 8. 10.3389/fphys.2017.00428

888 Semenza GL. 2014. Oxygen Sensing, Hypoxia-Inducible Factors, and Disease Pathophysiology. 889 Annual Review of Pathology: Mechanisms of Disease 9:47-71. 10.1146/annurev-pathol$890 \quad 012513-104720$

891 Shen Y, Qiu T, Liu X, Zhang L, Wang Z, and Zhou JJERMPS. 2018. Renal ischemia-reperfusion 892 893 injury attenuated by splenic ischemic preconditioning. European Review for Medical and Pharmacological Sciences 22:2134-2142.10.26355/eurrev_201804_14747

894

895

896

897

898

899

900

901

902

903

904

905

906

907

908

909

Van Draanen NA, and Hengst S. 2010. The Conversion of 1-Phenylalanine to (S)-2-Hydroxy-3-

910

911 phenylpropanoic Acid: A Simple, Visual Example of a Stereospecific SN2 Reaction.

912 Journal of Chemical Education 87:623-624. 10.1021/ed100167k 913

Sigma-Aldrich. 2018. L- $\alpha$-Hydroxyglutaric acid disodium salt. Available at https://www.sigmaaldrich.com/catalog/product/sigma/90790? lang=es\&region $=A R \& g c l i$ $d=C j 0 K C Q j w 5 s 3 c B R C A A R I s A B 8 Z j U 1 p o f Y \_n 2 Q i s j Y f R V r d s 7 S s t a h b 8 D V P P q 5 K 3 Y$ eXzWGOR9Ki_-8_6IaAn51EALw_wcB (accessed September 8th 2018).

Takasu C, Vaziri ND, Li S, Robles L, Vo K, Takasu M, Pham C, Farzaneh SH, Shimada M, Stamos MJ, and Ichii H. 2017. Treatment with dimethyl fumarate ameliorates liver ischemia/reperfusion injury. World J Gastroenterol 23:4508-4516.

10.3748/wjg.v23.i25.4508

Tang CY, Lai CC, Huang PH, Yang AH, Chiang SC, Huang PC, Tseng KW, and Huang CH. 2017. Magnolol Reduces Renal Ischemia and Reperfusion Injury via Inhibition of Apoptosis. Am J Chin Med 45:1421-1439. 10.1142/s0192415x1750077x

Torres-González L, Cienfuegos-Pecina E, Perales-Quintana MM, Alarcon-Galvan G, MuñozEspinosa LE, Pérez-Rodríguez E, and Cordero-Pérez P. 2018. Nephroprotective Effect of Sonchus oleraceus Extract against Kidney Injury Induced by Ischemia-Reperfusion in Wistar Rats. Oxidative Medicine and Cellular Longevity 2018:7. 10.1155/2018/9572803

Wang GL, and Semenza GL. 1995. Purification and Characterization of Hypoxia-inducible Factor 1. Journal of Biological Chemistry 270:1230-1237. 10.1074/jbc.270.3.1230 
914 Wei Q, and Dong Z. 2012. Mouse model of ischemic acute kidney injury: technical notes and 915 tricks. American Journal of Physiology - Renal Physiology 303:F1487-F1494.

$916 \quad 10.1152$ ajprenal.00352.2012

917 Welbourn C, Goldman G, Paterson I, Valeri C, Shepro D, and Hechtman H. 1991.

918 Pathophysiology of ischaemia reperfusion injury: central role of the neutrophil. British 919 journal of surgery 78:651-655. 10.1002/bjs. 1800780607

920 Williams L, Nguyen T, Li Y, Porter TN, and Raushel FM. 2006. Uronate isomerase: a 921 nonhydrolytic member of the amidohydrolase superfamily with an ambivalent 922 requirement for a divalent metal ion. Biochemistry 45:7453-7462. 10.1021/bi0605311

923

924

925

926

927

928

929

930

931

932

933

934

935

936

937

938

939

940

941

942

943

Xu W, Yang H, Liu Y, Yang Y, Wang P, Kim S-H, Ito S, Yang C, Wang P, Xiao M-T, Liu L-X, Jiang W-q, Liu J, Zhang J-y, Wang B, Frye S, Zhang Y, Xu Y-h, Lei Q-y, Guan K-L, Zhao S-m, and Xiong Y. 2011. Oncometabolite 2-Hydroxyglutarate Is a Competitive Inhibitor of alpha-Ketoglutarate-Dependent Dioxygenases. Cancer Cell 19:17-30. 10.1016/j.ccr.2010.12.014

Yildiz F, Coban S, Terzi A, Aksoy N, and Bitiren M. 2015. Protective Effect of Micronized Purified Flavonoid Fraction on Ischemia/Reperfusion Injury of Rat Liver. Transplantation Proceedings 47:1507-1510. 10.1016/j.transproceed.2015.04.062

Zhang J, Tang L, Li GS, and Wang J. 2018. The anti-inflammatory effects of curcumin on renal ischemia-reperfusion injury in rats. Renal Failure 40:680-686. 10.1080/0886022X.2018.1544565

Zhang T, Ma Y, Xu KQ, and Huang WQ. 2015. Pretreatment of parecoxib attenuates hepatic ischemia/reperfusion injury in rats. BMC Anesthesiol 15:165. 10.1186/s12871-015-01470

Zhang W, Petrovic J-M, Callaghan D, Jones A, Cui H, Howlett C, and Stanimirovic D. 2006. Evidence that hypoxia-inducible factor-1 (HIF-1) mediates transcriptional activation of interleukin-1 $\beta$ (IL-1 $\beta$ ) in astrocyte culturess. Journal of Neuroimmunology 174:63-73. 10.1016/j.jneuroim.2006.01.014

Zhu S-h, Zhou L-j, Jiang H, Chen R-j, Lin C, Feng S, Jin J, Chen J-h, and Wu J-y. 2014.

Protective effect of indomethacin in renal ischemia-reperfusion injury in mice. Journal of Zhejiang University Science B 15:735-742. 10.1631/jzus.B1300196 
944 Zollinger H. 1995. Dediazoniation Reactions Involving Diazonium Ion Intermediates: Section

945 7.5-7.8. In: Zollinger H, ed. Diazo Chemistry II: Aliphatic, Inorganic and

946 Organometallic Compounds: Wiley, 241-277.

947 
Figure 1

Sodium (S)-2-hydroxyglutarate synthesis.

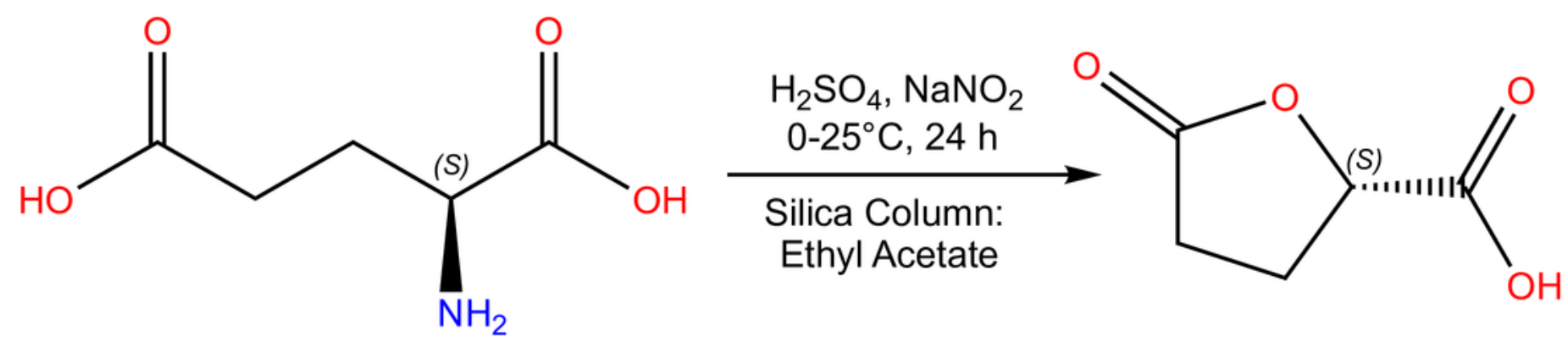<smiles>O=C([O-])CC[C@@H](O)C(=O)O[Na]</smiles> 


\section{Figure 2}

Biomarkers of kidney and liver injury after administration of sodium (S)-2hydroxyglutarate.

Values are expressed as mean \pm SD. The comparisons were between the 12.5Tox, 25Tox, and $\mathrm{SH}$ groups, and between the SH, 12.5+IR, 25+IR, and IR groups. One-way ANOVA test, Tukey post hoc test. (A) Effect of (S)-2HG treatment on the serum activity of ALT. (B) Effect of (S)-2HG treatment on the serum activity of AST; a) $p=0.0018$ vs SH group; b) $p=0.0081$ vs IR group. (C) Effect of (S)-2HG treatment on the serum concentration of BUN; a) $p<0.0001$ vs SH group; b) $p<0.0001$ vs IR group; c) $p<0.0001$ vs IR group. (D) Effect of (S)-2HG treatment on the serum concentration of creatinine; a) $p<0.0001$ vs SH group; b) $p=$ 0.0017 vs IR group; c) $p<0.0001$ vs IR group. (E) Effect of (S)-2HG treatment on the serum activity of ALP; a) $p=0.0010$ vs SH group; b) $p=0.0119$ vs IR group; c) $p 0.0394$ vs IR group. (F) Effect of (S)-2HG treatment on the serum activity of $L D H ;$ a) $p=0.0009$ vs $S H$ group; b) $p=0.0002$ vs IR group; c) $p=0.0240$ vs IR group. (S)-2HG = sodium (S)-2hydroxyglutarate; $\mathrm{ALT}=$ alanine aminotransferase; $\mathrm{AST}$ = aspartate aminotransferase; BUN = blood urea nitrogen; $\mathrm{ALP}=$ alkaline phosphatase; $\mathrm{LDH}=$ lactate dehydrogenase. 
A

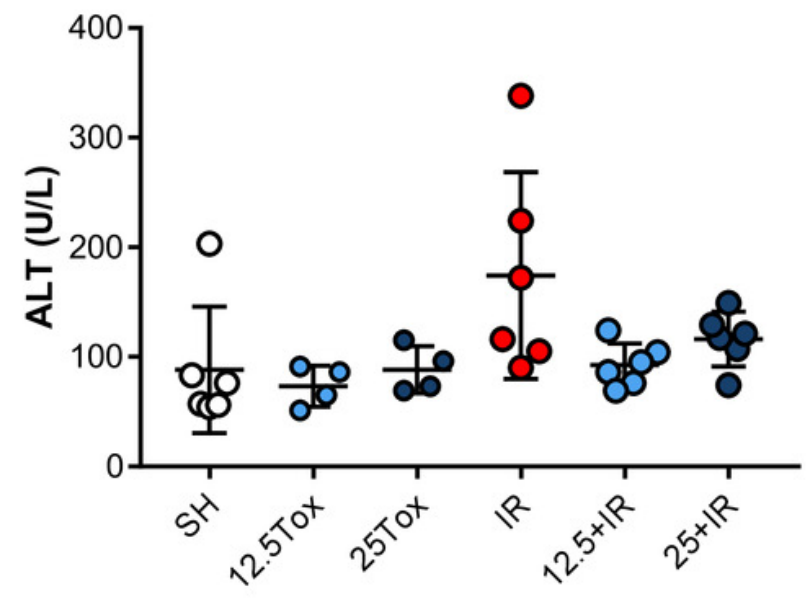

C

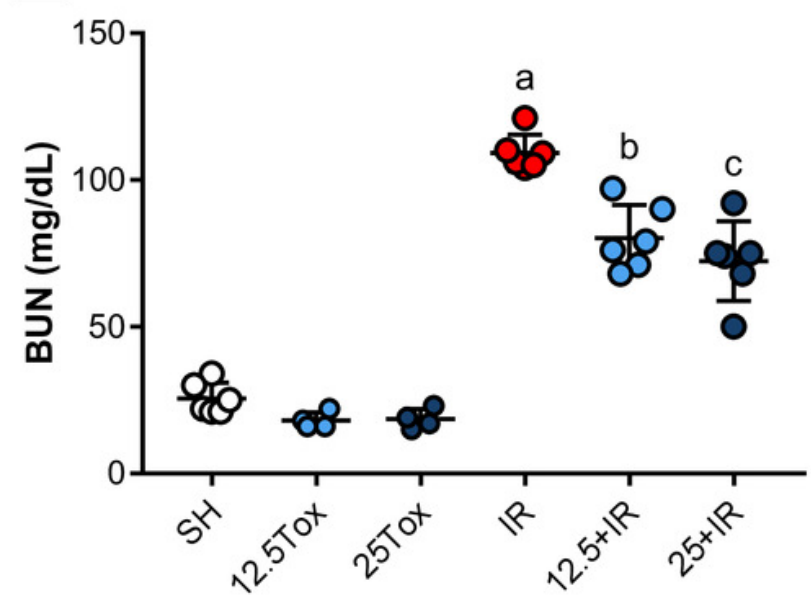

E

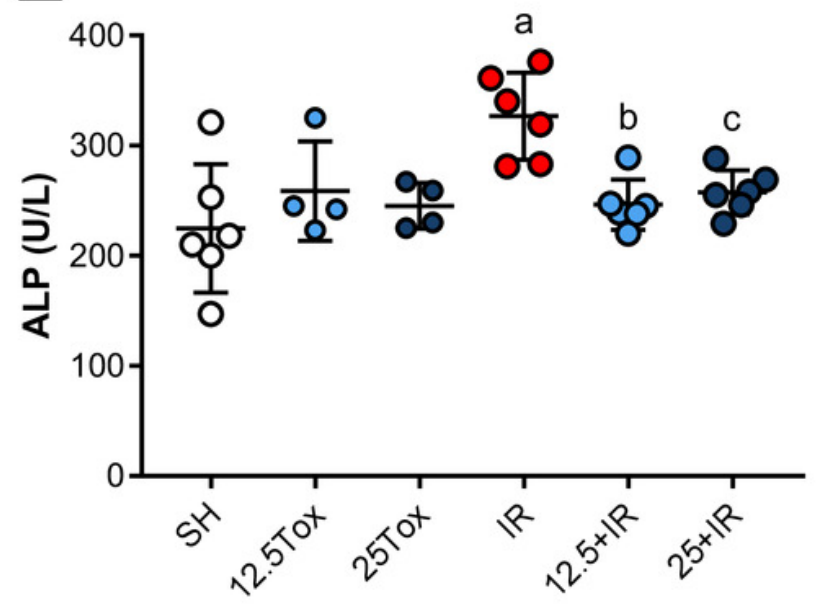

B

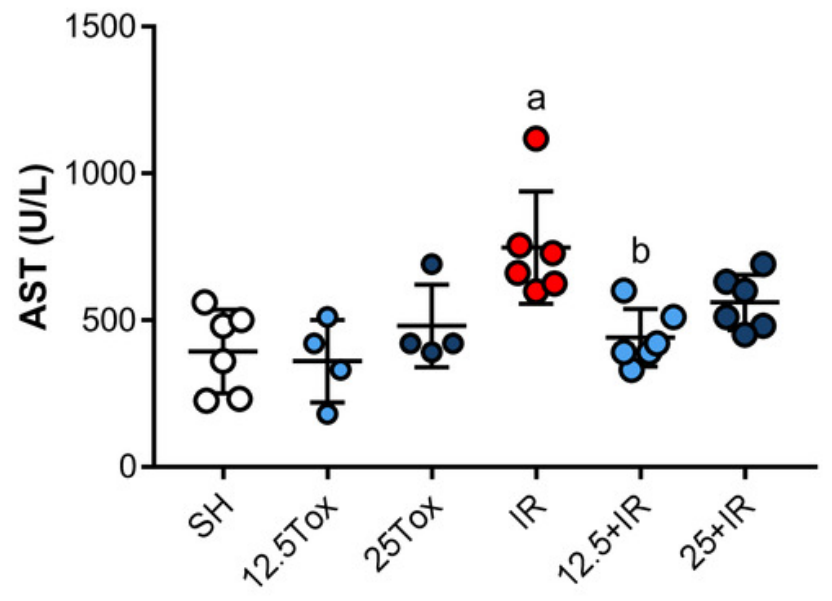

D

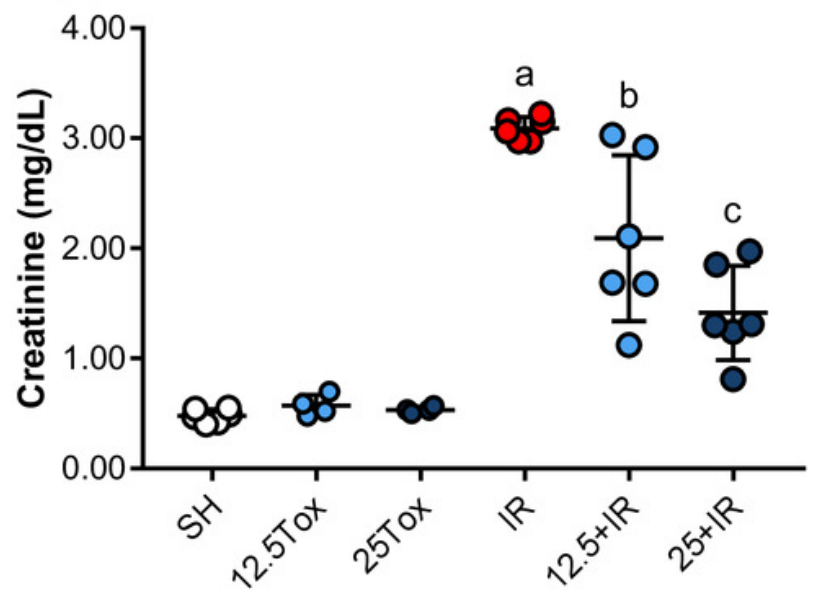

F

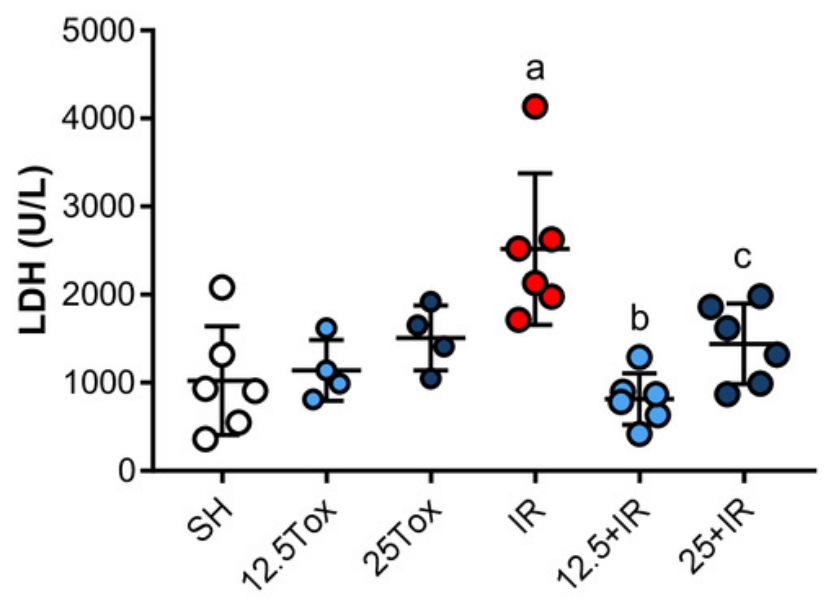




\section{Figure 3}

Microphotographs of renal histology in the sodium (S)-2-hydroxyglutarate-treated groups.

Hematoxylin and eosin staining (original magnification $\times 400$ ). Conserved tissue architecture was observed in (A) the SH group; (B) the 12.5Tox group; and (C) the 25Tox group. Diffuse and severe tubular necrosis was observed in (D) the IR group, and focal tubular necrosis in (E) the $12.5+$ IR group and (F) the $25+I R$ group. 

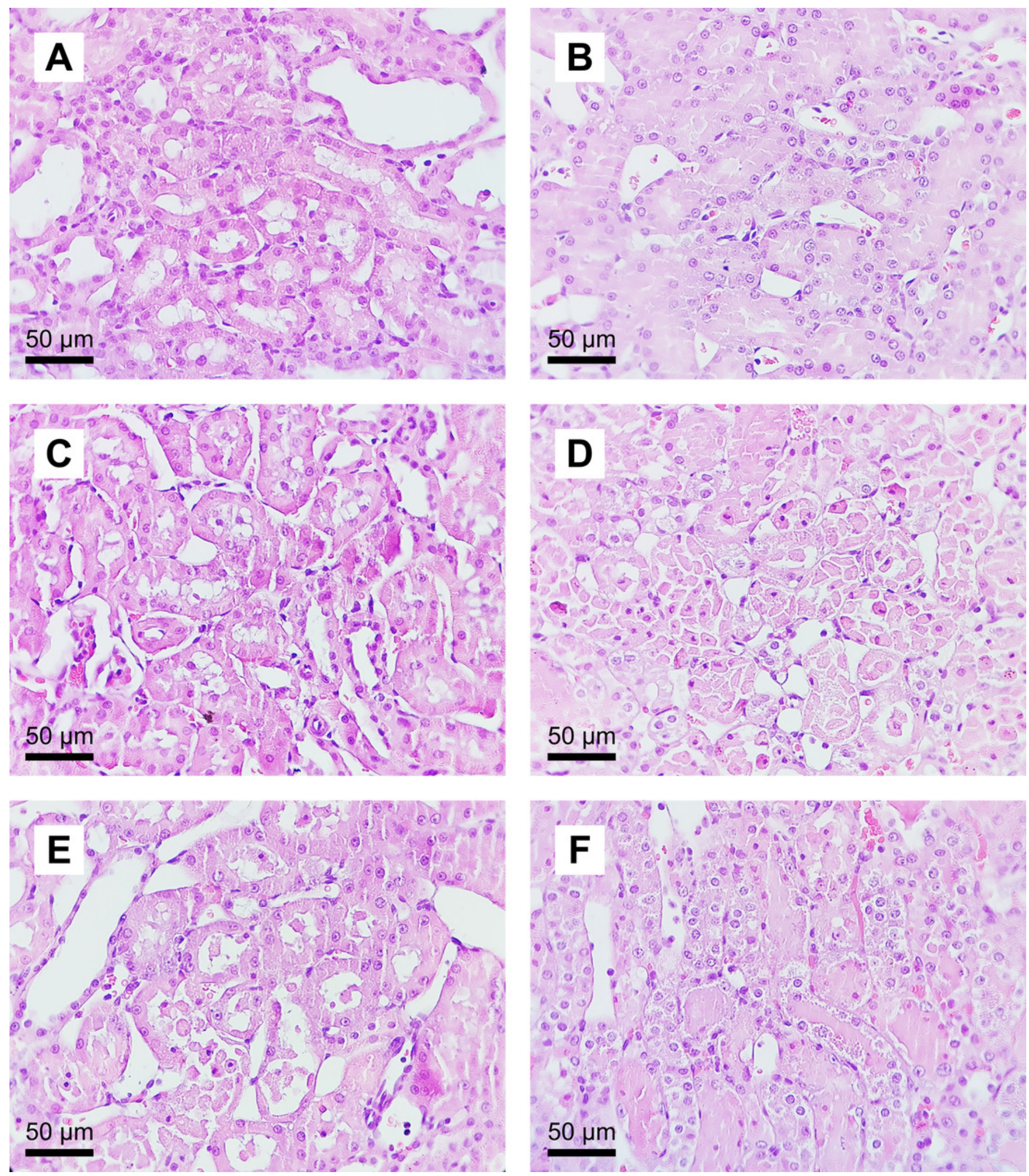
Figure 4

Tissue HIF-1 $\alpha$ concentrations measured by ELISA after administration of sodium (S)-2hydroxyglutarate.

Values are expressed as mean \pm SD. The comparisons were between the 12.5Tox, 25Tox, and $\mathrm{SH}$ groups, and between the SH, $12.5+\mathrm{IR}, 25+\mathrm{IR}$, and IR groups. One-way ANOVA test, Tukey post hoc test. a) $p=0.0114$ vs SH group; b) $p=0.0040$ vs SH group; c) $p=0.0211$ vs IR group. HIF-1 $\alpha=$ hypoxia-inducible factor $1 \alpha$.

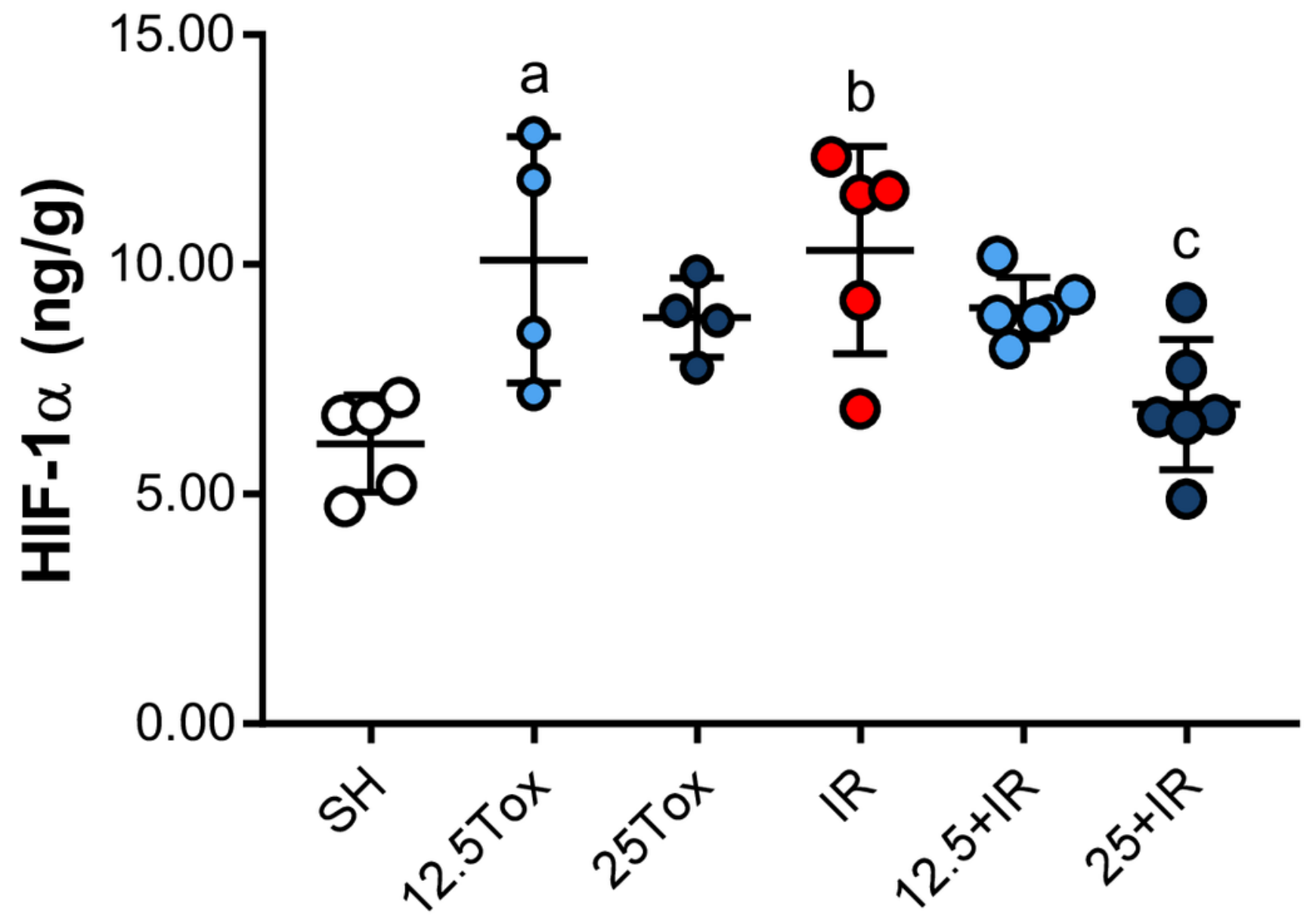




\section{Figure 5}

Tissue HIF-1 $\alpha$ expression assessed by Western blot after administration of sodium (S)-2hydroxyglutarate.

Values are expressed as mean \pm SD. The comparisons were between the 12.5Tox, 25Tox, and SH groups, and between the SH, 12.5+IR, 25+IR, and IR groups. One-way ANOVA test, Tukey post hoc test (data were logarithmically transformed prior to the statistical analysis). a) $p<0.0001$ vs SH group; b) $p=0.0001$ vs IR group; c) $p=0.0151$ vs IR group. HIF-1 $\alpha=$ hypoxia-inducible factor $1 \alpha$. 
IR injury induction $\quad-\quad \begin{array}{lllllll} & - & - & & + & + & +\end{array}$

(S)-2HG (mg/kg) $0 \quad 12.5 \quad 25 \quad 00012.5 \quad 25$

HIF-1a (55 kDa)

GAPDH (37 kDa)

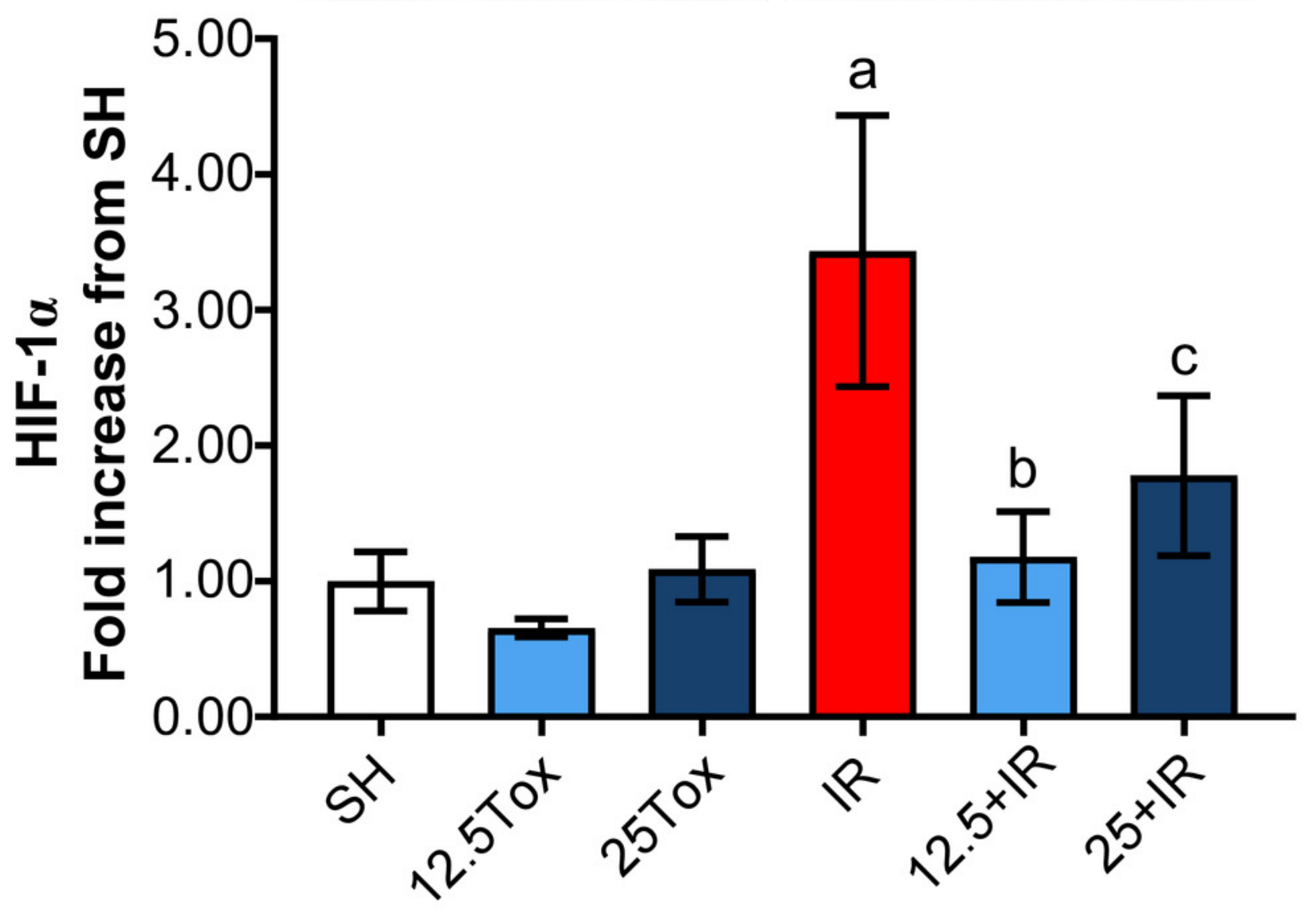




\section{Figure 6}

Tissue expression of Hmox1 assessed by RT-qPCR after administration of (S)-2hydroxyglutarate.

Values are expressed as mean \pm SD. The comparisons were between the 12.5Tox, 25Tox, and $\mathrm{SH}$ groups, and between the SH, 12.5+IR, 25+IR, and IR groups. One-way ANOVA test, Tukey post hoc test (data were logarithmically transformed prior to the statistical analysis). a) $p=0.0011$ vs SH group; b) $p<0.0001$ vs SH group. Hmox $1=$ heme oxygenase 1 .

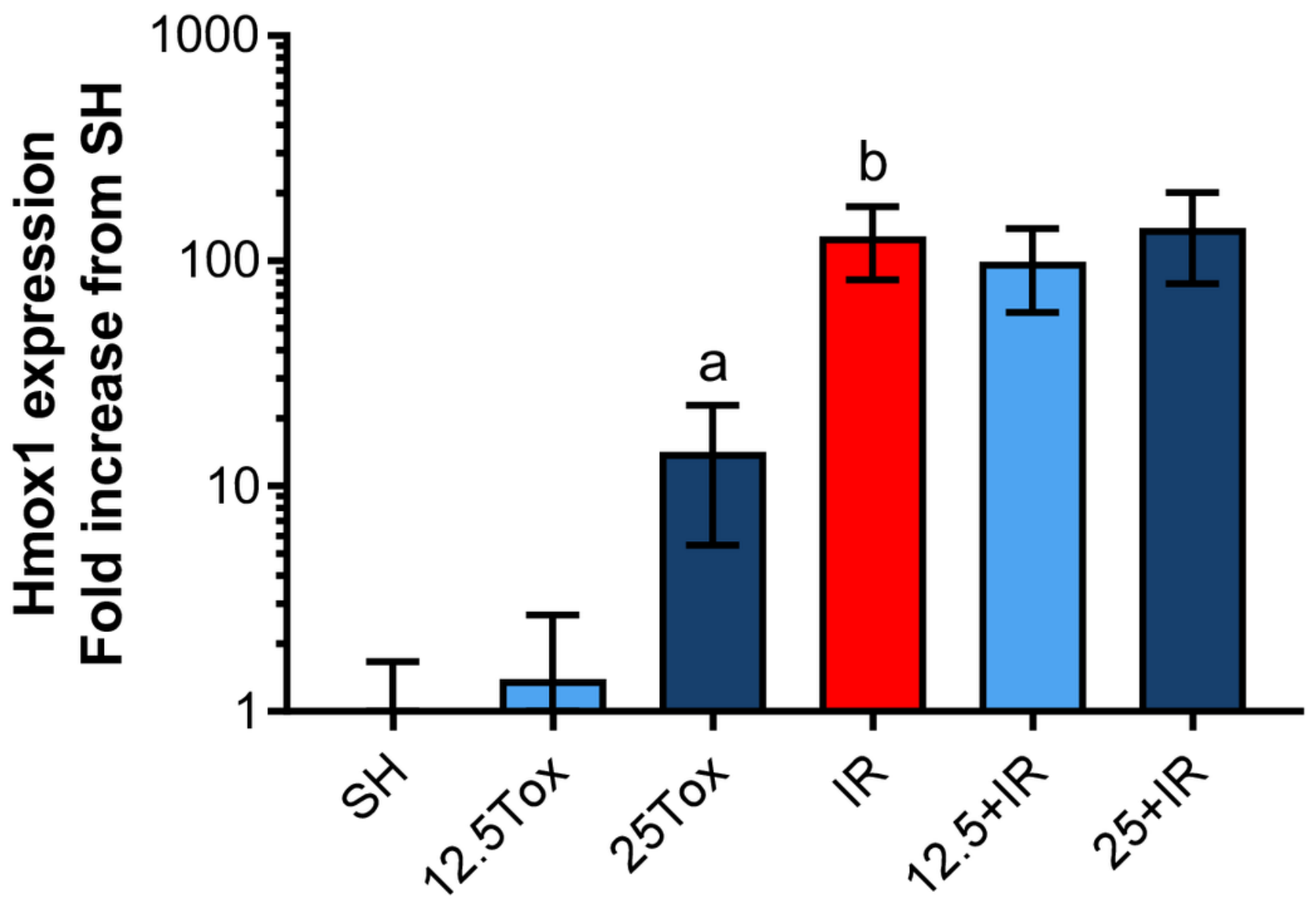




\section{Figure 7}

Biomarkers of kidney and liver injury after administration of succinic acid.

Values are expressed as mean \pm SD. The comparisons were between the 12.5Tox, 25Tox, 50Tox, and SH groups, and between the SH, 12.5+IR, 25+IR, 50+IR, and IR groups. One-way ANOVA test, Tukey post hoc test. (A) Effect of SA treatment on the serum activity of ALT. (B) Effect of SA treatment on the serum activity of AST. (C) Effect of SA treatment on the serum concentration of BUN; a) $p<0.0001$ vs SH group. (D) Effect of SA treatment on the serum concentration of creatinine; a) $p<0.0001$ vs SH group; b) $p=0.0288$ vs IR group. (E) Effect of SA treatment on the serum activity of ALP. (F) Effect of SA treatment on the serum activity of LDH. SA = succinic acid; ALT = alanine aminotransferase; $A S T$ = aspartate aminotransferase; $\mathrm{BUN}=$ blood urea nitrogen; $\mathrm{ALP}=$ alkaline phosphatase; $\mathrm{LDH}=$ lactate dehydrogenase. 
A

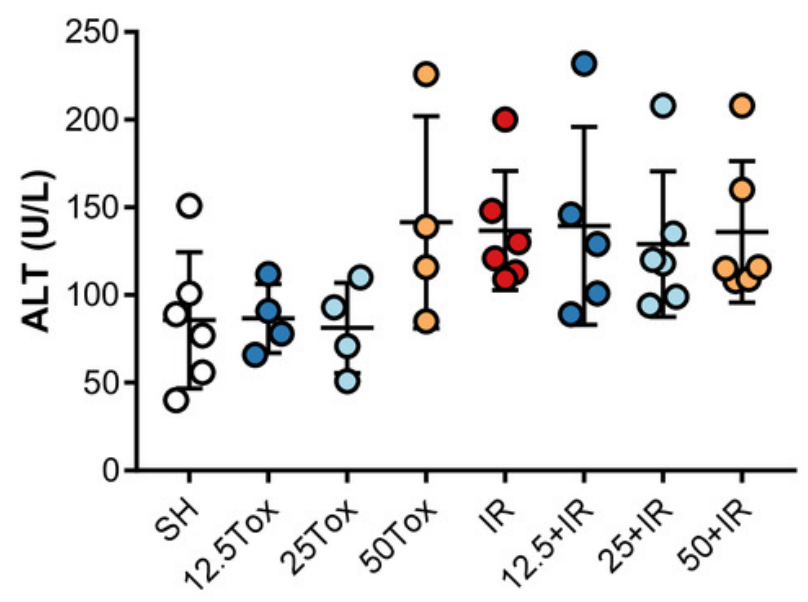

C

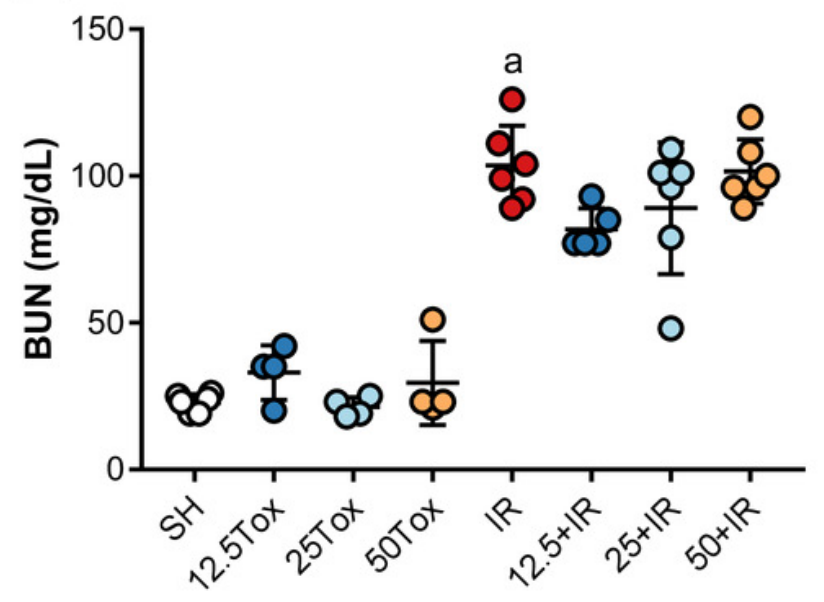

E

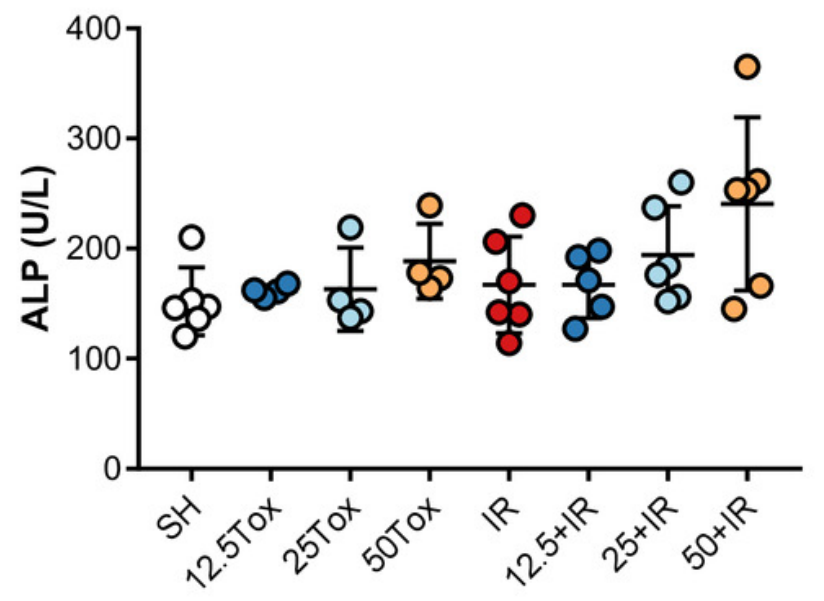

B

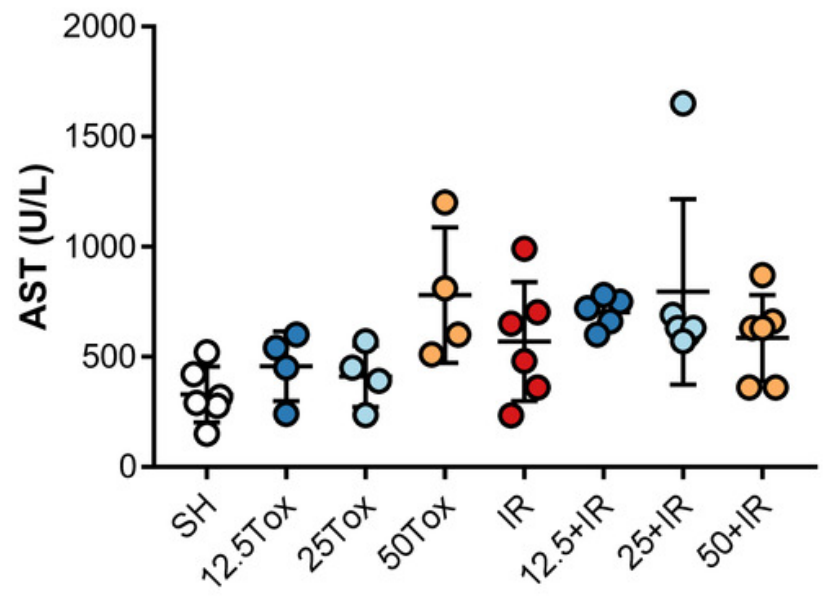

D

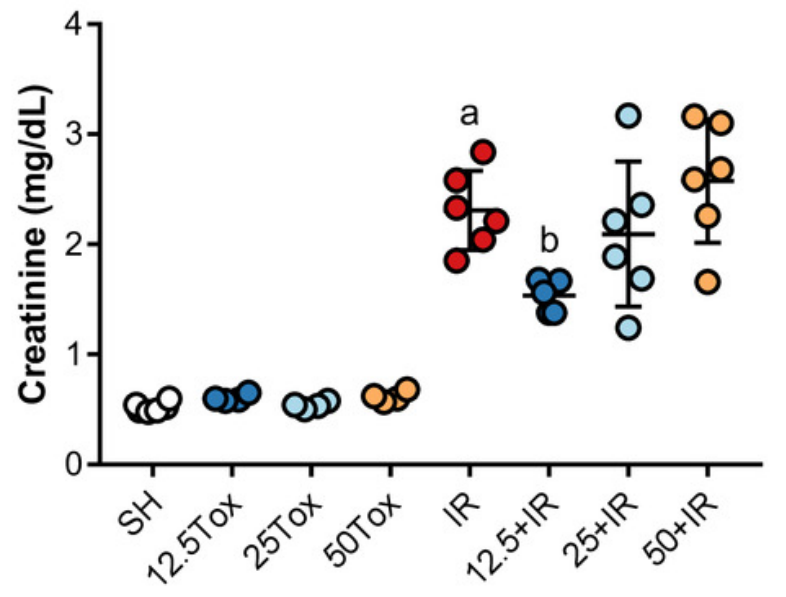

F

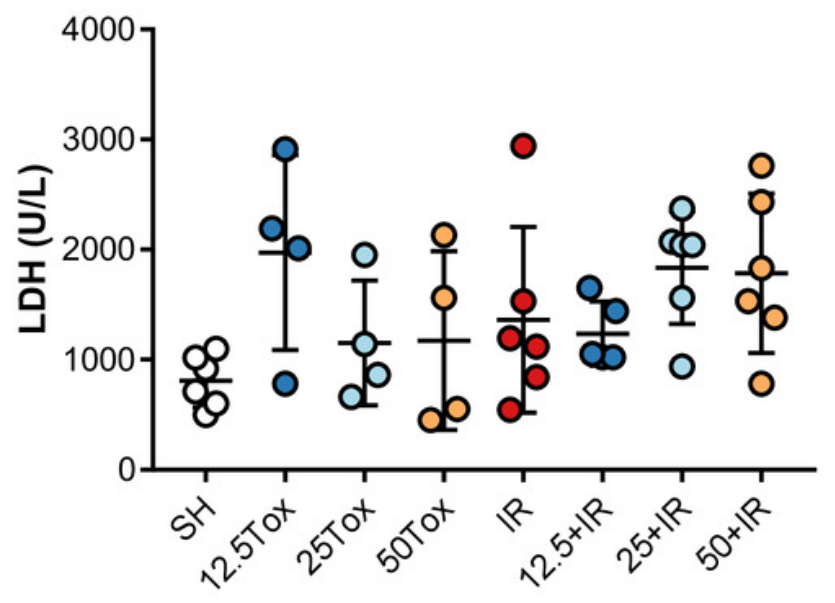




\section{Figure 8}

Microphotographs of the renal histology of the succinic acid-treated groups.

Hematoxylin and eosin staining (original magnification $\times 400$ ). Conserved tissue architecture was observed in (A) the SH group, (B) the 12.5Tox group, (C) the 25Tox group, and (D) the 50Tox group. Diffuse tubular necrosis was observed in (E) the IR group. Focal tubular necrosis was observed in (F) the 12.5+IR group. Moderate to diffuse tubular necrosis was observed in (G) the 25+IR group. Diffuse and severe tubular necrosis and loss of the microscopic architecture were observed in $(\mathrm{H})$ the 50+IR group. 

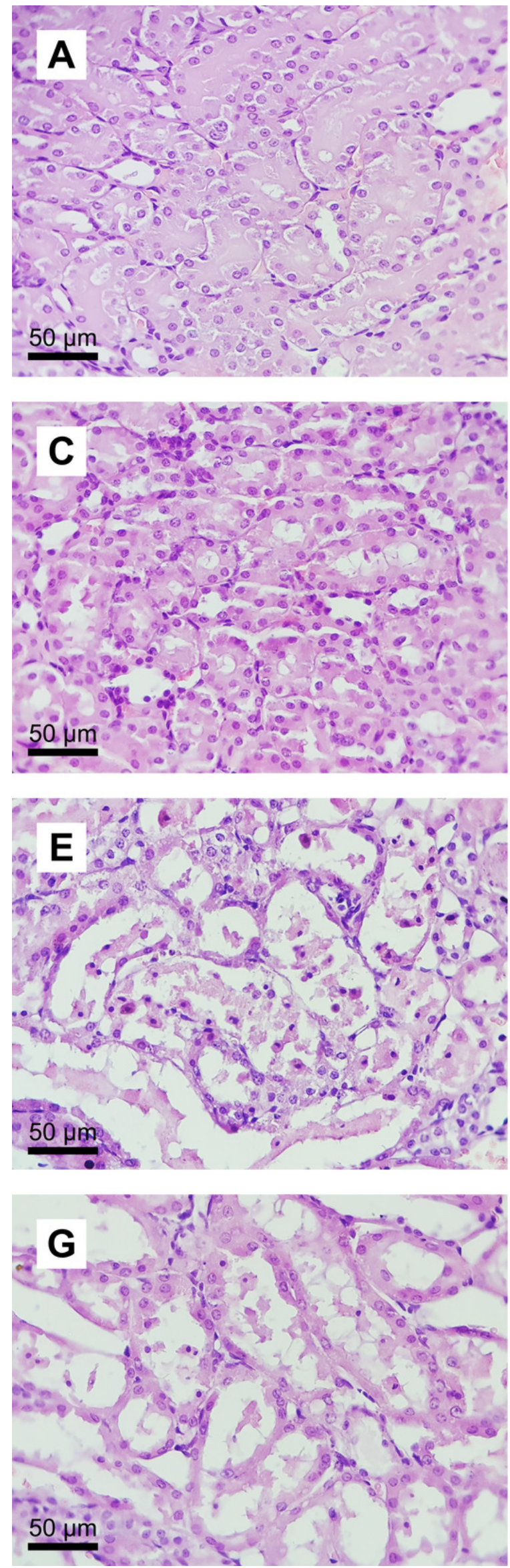
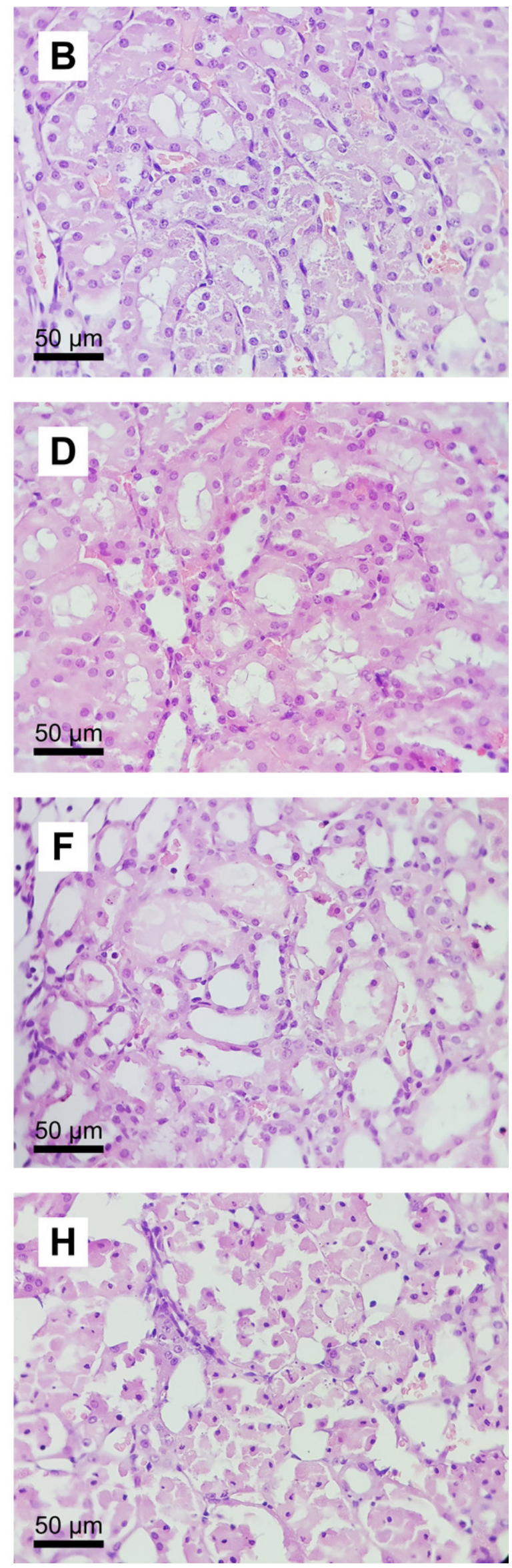


\section{Table $\mathbf{1}$ (on next page)}

Biomarkers of kidney and liver injury, oxidative stress biomarkers, and proinflammatory cytokines after administration of sodium (S)-2-hydroxyglutarate.

One-way ANOVA test, Tukey post hoc test. The comparisons were between the 12.5Tox, 25Tox, and SH groups, and between the SH, 12.5+IR, 25+IR, and IR groups. ALB = albumin; ALP = alkaline phosphatase; GLU = glucose; IL-1 $\beta$ = interleukin 1 $\beta$; IL-6 = interleukin 6; LDH $=$ lactate dehydrogenase MDA = malondialdehyde; SOD = superoxide dismutase; TNF $-\alpha=$ tumor necrosis factor $\alpha ; \mathrm{TP}=$ total proteins; UA $=$ uric acid. ${ }^{*} p=0.0358$ vs IR group. 
Table 1: Biomarkers of kidney and liver injury, oxidative stress biomarkers, and

2 proinflammatory cytokines after administration of $(S)-2 \mathrm{HG}$.

\begin{tabular}{lcccccc}
\hline Biomarker & SH & 12.5 Tox & 25 Tox & IR & $12.5+\mathrm{IR}$ & $25+\mathrm{IR}$ \\
\hline ALB $(\mathrm{g} / \mathrm{dL})$ & $3.0 \pm 0.1$ & $3.1 \pm 0.1$ & $3.1 \pm 0.2$ & $3.0 \pm 0.2$ & $3.0 \pm 0.1$ & $3.1 \pm 0.2$ \\
GLU $(\mathrm{mg} / \mathrm{dL})$ & $164 \pm 29$ & $193 \pm 31$ & $181 \pm 33$ & $134 \pm 37$ & $144 \pm 25$ & $134 \pm 24$ \\
TP $(\mathrm{g} / \mathrm{dL})$ & $5.3 \pm 0.2$ & $5.4 \pm 0.3$ & $5.8 \pm 0.3$ & $5.1 \pm 0.3$ & $5.2 \pm 0.2$ & $5.6 \pm 0.2^{*}$ \\
UA $(\mathrm{mg} / \mathrm{dL})$ & $0.6 \pm 0.1$ & $0.5 \pm 0.1$ & $0.6 \pm 0.2$ & $0.4 \pm 0.3$ & $0.4 \pm 0.1$ & $0.6 \pm 0.1$ \\
SOD $(\%)$ & $93 \pm 2$ & $91 \pm 1$ & $93 \pm 7$ & $95 \pm 3$ & $97 \pm 5$ & $95 \pm 6$ \\
MDA $(\mu \mathrm{mol} / \mathrm{g})$ & $75.48 \pm 25.75$ & $80.00 \pm 32.04$ & $70.63 \pm 24.12$ & $87.36 \pm 33.91$ & $86.13 \pm 25.48$ & $73.57 \pm 13.66$ \\
IL-1 $(\mathrm{ng} / \mathrm{mL})$ & $1.50 \pm 0.67$ & $1.50 \pm 0.41$ & $1.34 \pm 0.94$ & $2.19 \pm 1.57$ & $1.70 \pm 1.21$ & $1.51 \pm 0.73$ \\
IL-6 $(\mathrm{ng} / \mathrm{mL})$ & $3.44 \pm 1.26$ & $4.00 \pm 0.65$ & $2.91 \pm 1.33$ & $3.05 \pm 2.49$ & $2.49 \pm 0.45$ & $2.42 \pm 0.73$ \\
TNF- $\alpha(\mathrm{ng} / \mathrm{mL})$ & $0.78 \pm 0.35$ & $0.85 \pm 0.34$ & $1.02 \pm 0.92$ & $1.06 \pm 1.12$ & $0.61 \pm 0.55$ & $0.71 \pm 0.41$ \\
\hline
\end{tabular}

3 One-way ANOVA test, Tukey post hoc test. The comparisons were between the 12.5Tox, 25Tox, and SH groups, and between 4 the SH, 12.5+IR, 25+IR, and IR groups. ALB = albumin; ALP = alkaline phosphatase; GLU = glucose; IL-1 $\beta=$ interleukin $1 \beta$;

5 IL-6 = interleukin 6; $\mathrm{LDH}=$ lactate dehydrogenase; MDA = malondialdehyde; SOD = superoxide dismutase; TNF- $\alpha=$ tumor

6 necrosis factor $\alpha$;P $=$ total proteins; $\mathrm{UA}=$ uric acid. ${ }^{*} p=0.0358$ vs IR group. 


\section{Table 2 (on next page)}

Evaluation of renal histopathology after administration of sodium (S)-2hydroxyglutarate.

Kruskal-Wallis test, Dunn post hoc test. Values expressed as median (interquartile range). The comparisons were between the 12.5Tox, 25Tox, and SH groups, and between the SH, $12.5+I R, 25+I R$, and IR groups. Significant differences when comparing IR vs. SH group: $t p=$ 0.0002 and $\neq p=0.0016$. 
1

Table 2: Evaluation of renal histopathology after administration of $(S)$-2HG.

\begin{tabular}{lcccccc}
\hline Parameter & SH & 12.5 Tox & 25 Tox & IR & $12.5+$ IR & $25+$ IR \\
\hline Tubular Necrosis & $0.00(0.00-$ & $0.00(0.00-$ & $0.00(0.00-$ & $4.00(4.00-$ & $2.50(1.75-$ & $2.50(1.75-$ \\
& $0.00)$ & $0.75)$ & $0.00)$ & $4.00) \dagger$ & $3.00)$ & $3.00)$ \\
& & & & & & \\
Acidophilic Casts & $0.00(0.00-$ & $0.50(0.00-$ & $0.00(0.00-$ & $4.00(3.00-$ & $3.00(1.75-$ & $2.00(2.00-$ \\
& $0.50)$ & $1.75)$ & $0.00)$ & $4.00) \ddagger$ & $3.25)$ & $2.25)$ \\
Vascular & & & & & \\
Congestion & $1.00(0.00-$ & $0.50(0.00-$ & $0.50(0.00-$ & $2.00(1.00-$ & $2.00(1.75-$ & $1.00(1.00-$ \\
& $1.25)$ & $1.75)$ & $1.00)$ & $4.00)$ & $2.00)$ & $2.00)$
\end{tabular}

2 Kruskal-Wallis test, Dunn post hoc test. Values expressed as median (interquartile range). The comparisons were between the

3 12.5Tox, 25Tox, and SH groups, and between the SH, 12.5+IR, 25+IR, and IR groups. Significant differences when comparing 4 IR vs. SH group: $\pitchfork p=0.0002$ and $\ddagger p=0.0016$.

5 


\section{Table 3 (on next page)}

Biomarkers of kidney and liver injury, oxidative stress biomarkers, and proinflammatory cytokines after administration of succinic acid.

One-way ANOVA test, Tukey post hoc test. The comparisons were between the 12.5Tox, 25Tox, 50Tox, and SH groups, and between the SH, 12.5+IR, 25+IR, 50+IR, and IR groups. $A L B=$ albumin; $A L P=$ alkaline phosphatase; $G L U=$ glucose; IL-1 $1 \beta=$ interleukin $1 \beta ; \mathrm{IL}-6=$ interleukin 6; $\mathrm{LDH}=$ lactate dehydrogenase; $\mathrm{MDA}=$ malondialdehyde; $\mathrm{SOD}=$ superoxide dismutase; TNF- $\alpha=$ tumor necrosis factor $\alpha ; \mathrm{TP}=$ total proteins; UA $=$ uric acid. ${ }^{*} p=0.0293$ vs SH. 
Table 3: Biomarkers of kidney and liver injury, oxidative stress biomarkers, and

2 proinflammatory cytokines after administration of SA.

\begin{tabular}{|c|c|c|c|c|c|c|c|c|}
\hline Biomarker & $\mathrm{SH}$ & 12.5Tox & 25Tox & 50Tox & IR & $12.5+\mathrm{IR}$ & $25+\mathrm{IR}$ & $50+\mathrm{IR}$ \\
\hline ALB (g/dL) & $3.1 \pm 0.1$ & $3.1 \pm 0.2$ & $3.1 \pm 0.2$ & $3.3 \pm 0.1$ & $3.1 \pm 0.2$ & $3.0 \pm 0.2$ & $3.0 \pm 0.2$ & $3.0 \pm 0.1$ \\
\hline $\begin{array}{l}\text { GLU } \\
(\mathrm{mg} / \mathrm{dL})\end{array}$ & $153 \pm 15$ & $128 \pm 57$ & $149 \pm 29$ & $143 \pm 22$ & $92 \pm 15 *$ & $103 \pm 15$ & $101 \pm 30$ & $92 \pm 44$ \\
\hline $\mathrm{TP}(\mathrm{g} / \mathrm{dL})$ & $5.5 \pm 0.1$ & $5.2 \pm 0.5$ & $5.3 \pm 0.3$ & $5.9 \pm 0.3$ & $5.2 \pm 0.4$ & $5.2 \pm 0.2$ & $5.3 \pm 0.3$ & $5.2 \pm 0.1$ \\
\hline $\begin{array}{l}\mathrm{UA} \\
(\mathrm{mg} / \mathrm{dL})\end{array}$ & $0.7 \pm 0.2$ & $0.8 \pm 0.2$ & $0.5 \pm 0.1$ & $0.6 \pm 0.2$ & $1.1 \pm 0.6$ & $0.5 \pm 0.1$ & $0.6 \pm 0.2$ & $0.8 \pm 0.6$ \\
\hline SOD $(\%)$ & $94 \pm 2$ & $88 \pm 4$ & $91 \pm 3$ & $90 \pm 1$ & $97 \pm 2$ & $92 \pm 1$ & $88 \pm 10$ & $91 \pm 4$ \\
\hline $\begin{array}{l}\text { MDA } \\
(\mu \mathrm{mol} / \mathrm{g})\end{array}$ & $72.71 \pm 9.71$ & $88.80 \pm 14.81$ & $85.13 \pm 9.87$ & $92.10 \pm 16.63$ & $145.54 \pm 97.83$ & $71.89 \pm 16.91$ & $71.64 \pm 18.49$ & $102.46 \pm 24.30$ \\
\hline $\begin{array}{l}\mathrm{IL}-1 \beta \\
(\mathrm{ng} / \mathrm{mL})\end{array}$ & $1.32 \pm 0.70$ & $2.28 \pm 1.05$ & $2.46 \pm 0.29$ & $4.06 \pm 3.08$ & $1.50 \pm 0.42$ & $1.19 \pm 0.43$ & $1.08 \pm 0.48$ & $0.83 \pm 0.42$ \\
\hline $\begin{array}{l}\text { IL-6 } \\
\text { (ng/mL) }\end{array}$ & $3.31 \pm 1.37$ & $3.06 \pm 1.01$ & $3.08 \pm 0.86$ & $4.15 \pm 0.89$ & $3.93 \pm 0.72$ & $2.26 \pm 0.88$ & $2.15 \pm 0.85$ & $1.95 \pm 0.92$ \\
\hline $\begin{array}{l}\text { TNF- } \alpha \\
(\mathrm{ng} / \mathrm{mL})\end{array}$ & $0.77 \pm 0.46$ & $0.52 \pm 0.19$ & $0.70 \pm 0.17$ & $1.24 \pm 0.63$ & $0.92 \pm 0.54$ & $0.37 \pm 0.18$ & $0.30 \pm 0.17$ & $0.89 \pm 1.36$ \\
\hline
\end{tabular}

3 One-way ANOVA test, Tukey post hoc test. The comparisons were between the 12.5Tox, 25Tox, 50Tox, and SH groups, and

4 between the SH, 12.5+IR, 25+IR, 50+IR, and IR groups. ALB = albumin; ALP = alkaline phosphatase; GLU = glucose; IL-1 $\beta=$

5 interleukin 1 $\beta$; IL-6 = interleukin 6; LDH = lactate dehydrogenase; MDA = malondialdehyde; SOD = superoxide dismutase;

$6 \mathrm{TNF}-\alpha=$ tumor necrosis factor $\alpha$; TP $=$ total proteins; UA $=$ uric acid. ${ }^{*} p=0.0293 \mathrm{vs} \mathrm{SH}$. 


\section{Table 4 (on next page)}

Evaluation of renal histopathology after administration of succinic acid.

Kruskal-Wallis test, Dunn post hoc test. Values expressed as median (interquartile range).

The comparisons were between the 12.5Tox, 25Tox, 50Tox, and SH groups, and between the $\mathrm{SH}, 12.5+\mathrm{IR}, 25+\mathrm{IR}, 50+\mathrm{IR}$, and IR groups. Significant differences when comparing IR vs. SH group: $* p=0.0297$. 
1

Table 4: Evaluation of renal histopathology after administration of SA.

\begin{tabular}{|c|c|c|c|c|c|c|c|c|}
\hline Parameter & $\mathrm{SH}$ & 12.5Tox & 25Tox & 50Tox & IR & $12.5+\mathrm{IR}$ & $25+I R$ & $50+$ IR \\
\hline $\begin{array}{l}\text { Tubular } \\
\text { Necrosis }\end{array}$ & $\begin{array}{c}0.00(0.00- \\
0.00)\end{array}$ & $\begin{array}{c}0.00(0.00- \\
0.75)\end{array}$ & $\begin{array}{c}0.00(0.00- \\
0.00)\end{array}$ & $\begin{array}{c}0.00(0.00- \\
0.75)\end{array}$ & $\begin{array}{c}3.50(3.00- \\
4.00)^{*}\end{array}$ & $\begin{array}{c}3.00(2.50- \\
3.50)\end{array}$ & $\begin{array}{c}3.50(3.00- \\
4.00)\end{array}$ & $\begin{array}{c}4.00(3.75- \\
4.00)\end{array}$ \\
\hline $\begin{array}{l}\text { Acidophilic } \\
\text { Casts }\end{array}$ & $\begin{array}{c}0.00(0.00- \\
0.50)\end{array}$ & $\begin{array}{c}0.00(0.00- \\
0.00)\end{array}$ & $\begin{array}{c}0.00(0.00- \\
0.75)\end{array}$ & $\begin{array}{c}0.00(0.00- \\
0.00)\end{array}$ & $\begin{array}{c}2.00(2.00- \\
3.00)\end{array}$ & $\begin{array}{c}2.00(1.50- \\
3.00)\end{array}$ & $\begin{array}{c}3.00(2.75- \\
3.25)\end{array}$ & $\begin{array}{c}2.00(2.00- \\
2.50)\end{array}$ \\
\hline $\begin{array}{l}\text { Vascular } \\
\text { Congestion }\end{array}$ & $\begin{array}{c}1.00(0.75- \\
2.00)\end{array}$ & $\begin{array}{c}1.00(0.25- \\
1.75)\end{array}$ & $\begin{array}{c}0.50(0.00- \\
1.00)\end{array}$ & $\begin{array}{c}1.00(0.25- \\
1.75)\end{array}$ & $\begin{array}{c}1.50(0.00- \\
3.00)\end{array}$ & $\begin{array}{c}2.00(1.00- \\
2.00)\end{array}$ & $\begin{array}{c}1.50(0.75- \\
3.25)\end{array}$ & $\begin{array}{c}3.00(1.50 \\
4.00)\end{array}$ \\
\hline
\end{tabular}

2 Kruskal-Wallis test, Dunn post hoc test. Values expressed as median (interquartile range). The comparisons were between the 3 12.5Tox, 25Tox, 50Tox, and SH groups, and between the SH, 12.5+IR, 25+IR, 50+IR, and IR groups. Significant differences 4 when comparing IR vs. SH group: * $p=0.0297$. 